\section{الثقافة البيئية لدى طلبة كلية التربية فِ جامعة اليرموك \\ سالم الخوالده \\ * علي العمري

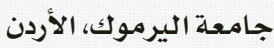

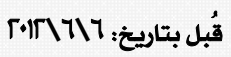

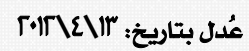

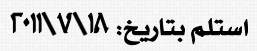

هدفت هذه الدراسة إلى تعرف مستوى الثقافة البيئية، لدى طلبة كلية التربية ِِّ جامعة اليرموك. أعدَّ الباحثان أداة لقياس

مستوى الثقافة البيئية تكونت من أربعة أجزاء هي: اختبار المعرفة البيئية، ومقياس الاتجاهات نحو البيئة، ومقياس الممارسة البيئية،

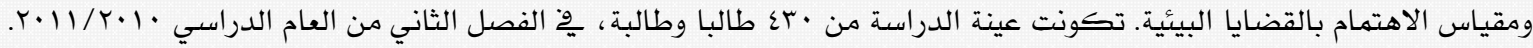

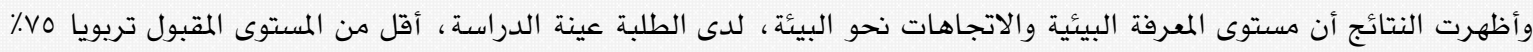

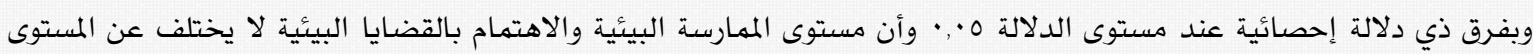

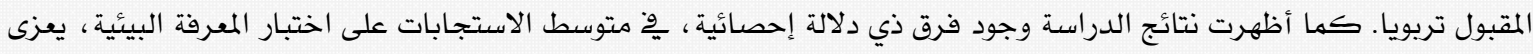

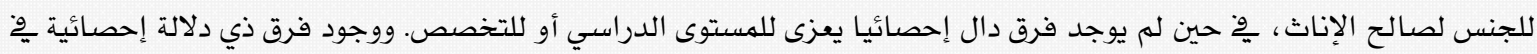

متوسط الاستجابات على مقياس الاتجاهات نحو البيئة يعزى للتخصص، عِ حين للم يوجد فرق دال يعزى للمستوى الدراسي أو

للجنس. ووجود فرق ذي دلالة إحصائية يوْ متوسط الاستجابات على مقياس الاهتمام بالقضايا البيئية ، يعزى للجنس لصالح الإناث

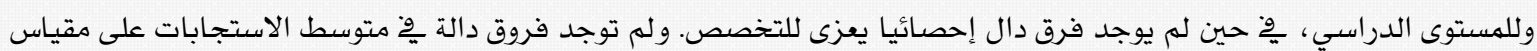

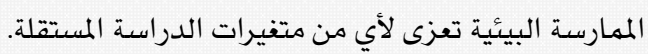

الكلمات المفتاحيه: الثقافة البيئية، المعرفة البيئية، الاجخاهات خو البيئة، الاهتمام بالبيئية.

\title{
Environmental Literacy among Students of the Faculty of Education at Yarmouk University
}

\author{
Ali. A. Al - Omari* \\ Salem. A. Al khawaldeh \\ Yarmouk University, Jordan \\ Al al-Bayt University, Jordan
}

This study aimed at examining the environmental literacy among students of the Faculty of Education at Yarmouk University. The researchers designed a four-part instrument for measuring environmental literacy consisting of: environmental knowledge, attitude towards the environment, environmental practices, and a concern for environmental issues. The sample of the study consisted of 430 male and female students in the second semester of the academic year 2010/2011.The findings revealed that the subjects' level of environmental knowledge and attitudes towards the environment are below the accepted educational standard $75 \%$ with a statistically significant difference $(\alpha=0.05)$, and that the level of environmental practices matches the accepted educational standard. The findings also showed a statistically significant difference in the mean scores on environmental knowledge scale due to gender in favor of female, while no differences were found due to the variables of year of study and specialization. A statistically significant difference was also found in the means of the subjects' responses on attitudes towards the environment scale due to specialization while no differences were found due to year of study and gender. Unlike specialization, both year of study and gender were found to cause a statistically significant difference in the means of the subjects' responses to the concern for environmental issues scale in favor of female respondents. N one of the variables of the study was found to make any statistically significance differences in the means of the subjects' responses to the environmental practices scale.

Keywords: environmental literacy, environmental knowledge, environmental attitudes, environmental concern.

*ali64omari@yahoo.com 
المناسبة للمحافظة عليها، وإعادتها إلى حالتها

$$
\text { الأصلية، أو خسـين صـحتها. }
$$

والصـورة الثانية كانت تقديم معنى الثقافة البئية من خلال خديد خصائص الفرد المثقف بيئيا وسـماته. (Harvery, 1976; Roth, 1984; وقد حدد التربويون خلاندان 1991 19ungerford \& Tomera, 1985

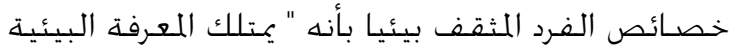

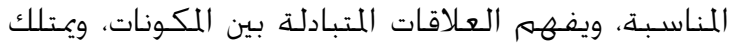
المهارات الضـرورية للتفاعل الإيجابي بين الإنسان والبيئة.

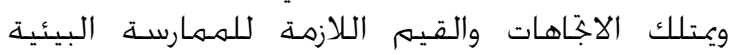

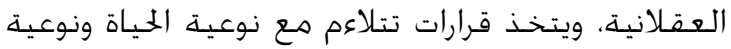

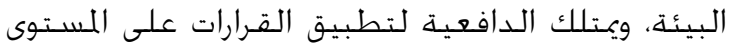

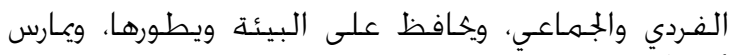

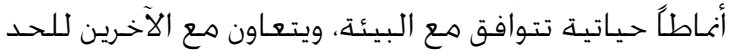

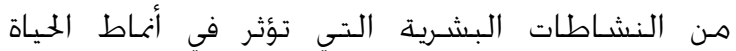
المختلفة.

أما الصـورة الثالثة فكانت تقديم معنى الثقافة

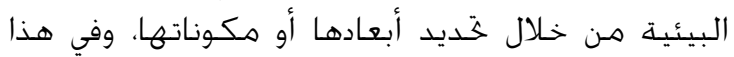

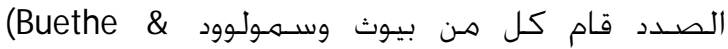

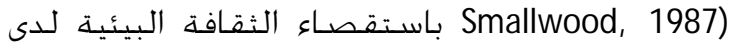

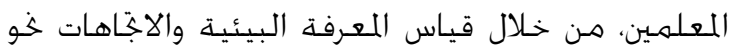

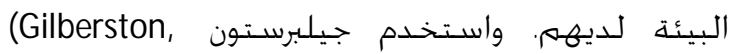

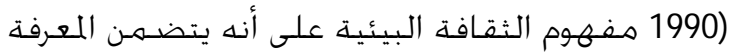

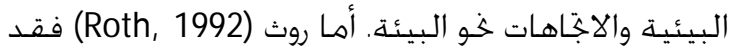

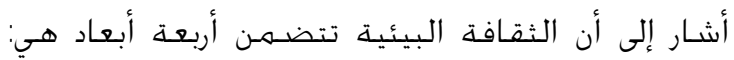

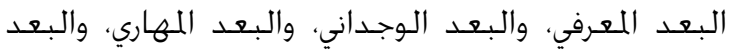

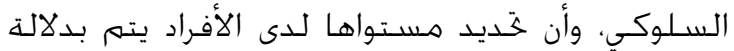

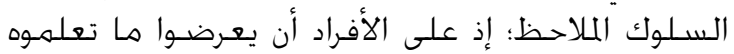

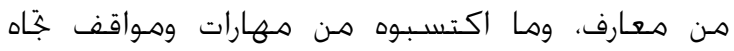
القضايا البيئية. في حين حدد ديزنقر (Disinger, 1992) ستة أبعاد للثقافة البئية هي: العـرفة، والمهارات.

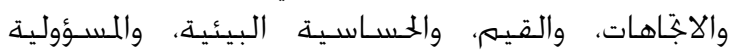

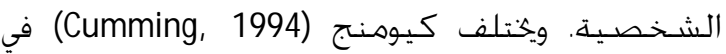

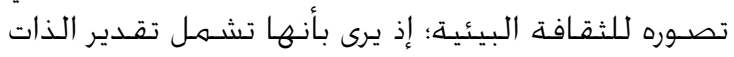

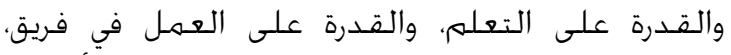

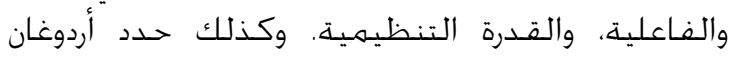
ورفاقه (Erdogan, et al, 2009) ستة أبعاد للثقافة التخان

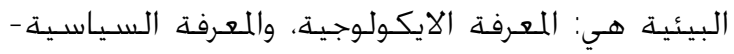

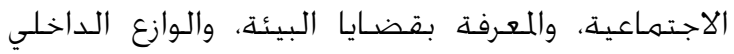
للعمل، والمهارات المعرفية، والسـلوك البيئي المسؤول.

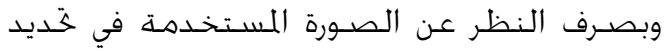

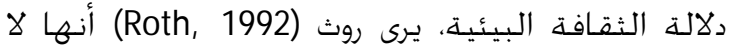

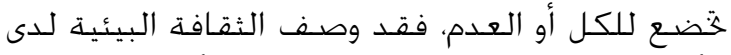

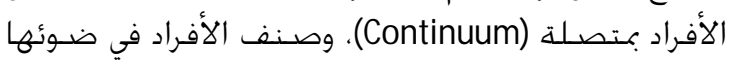

ورد في المعجم الوسيط بأن الثقافة هي العلوم

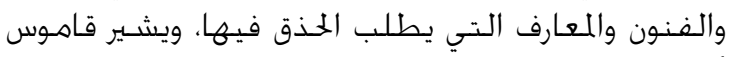

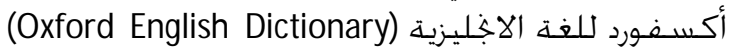
إلى أن الثقافة (Literacy) هي القدرة على القائل القراءة

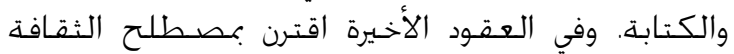

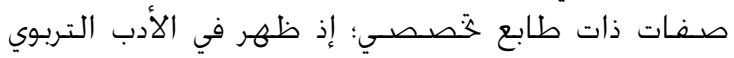

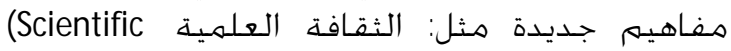

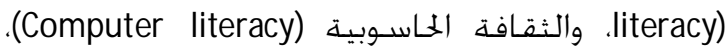
والثقافة البيولوجية (Biologic Literacy)، والثقافة الثة (Environm) البيئية (Environmental Literacy).

ظمهر مفهوم الثقافة البئية Environmental

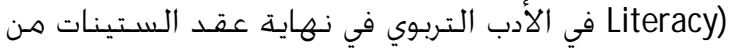

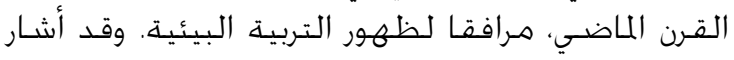

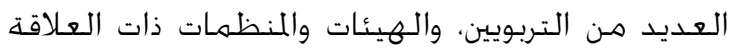

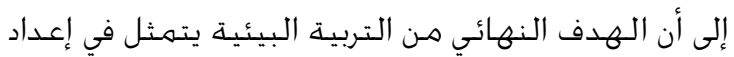
الإنسان المثقف بيئيا UNESCO, 1980; Disinger \& Roth, 1992; NAAEE, 2004; Coyle, 2005)

وفي الوقت الحاضر، أصبح إعداد الفرد المثقف بيئيا

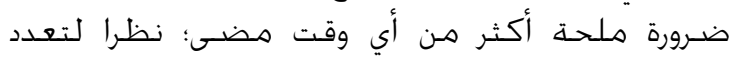

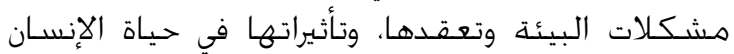

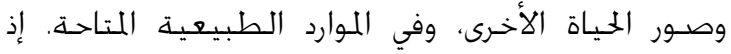

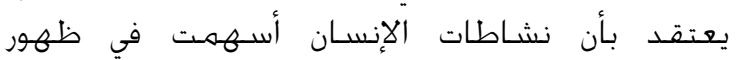

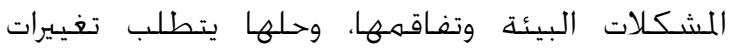
وتعديلات في أنماط السـلوك البيئي لدى الأفراد (الطائي

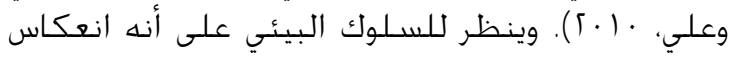

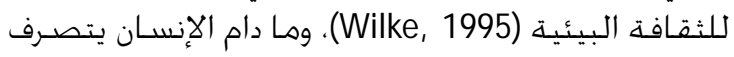

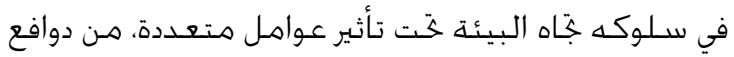

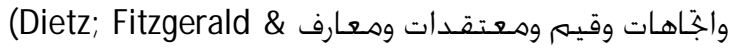

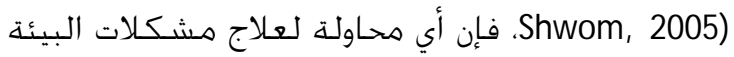

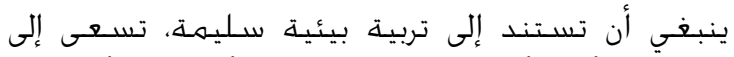

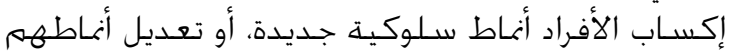
السـلوكية السـابقة.

وقد تعددت دلالات الثقافة البيئية لدى التربويين،

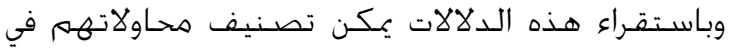

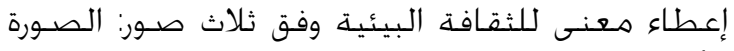

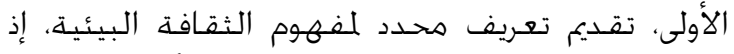

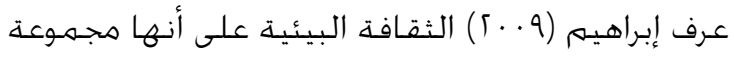

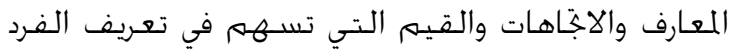

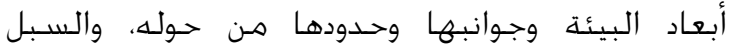

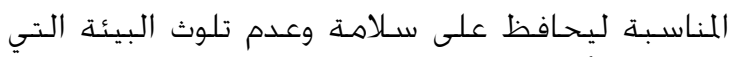
خيط به. أما ديزنقر وروث (Disinger \& Roth, 1992)

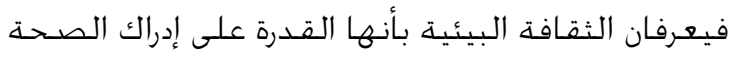

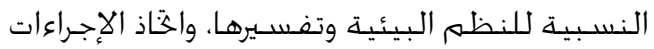


والتكنولوجيا والجُتمع والبيئة، وطبيعـة العلم)، لدى عينة

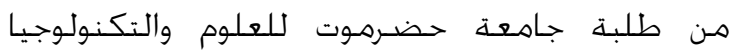
باليمـن. ووجـد أن مسـتوى الثقافة البئيـة، كان متدنيا

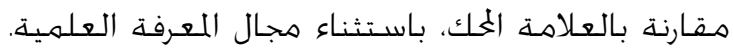

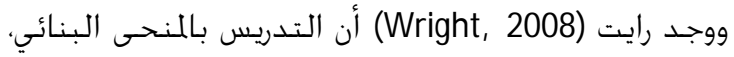

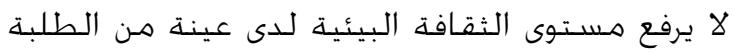

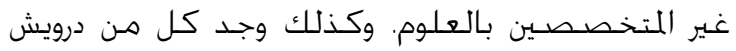

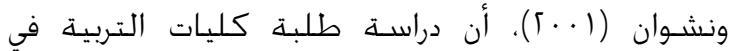

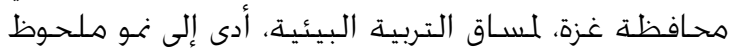

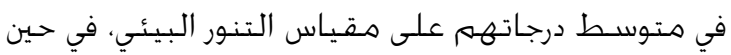
أن دراسـة ذلك المسـاق لم تؤثر في اكتسـاب الطلبة دئة للاجمّاهات البئيـة.

كما اسـتهدفت بعض الـدراسـات المعلمـين بوجـه عام،

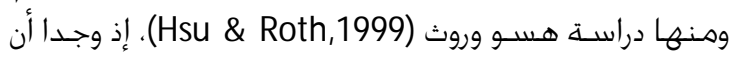

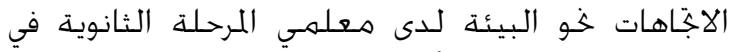

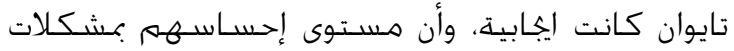

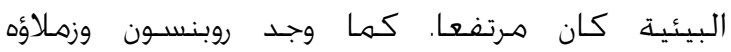
(Robinson et al, 2007)

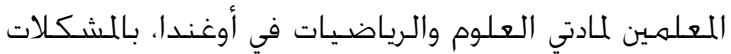

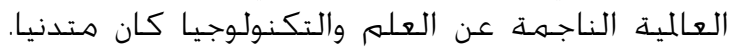
(Michail; ووجـ كل هن ميشيل وسـتاهوا وسـتاهوا Stamou \& Stamou, 2007) منطقة حضـرية باليونان، يمتلكون مفاهيم خاطئة فيما

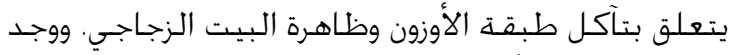

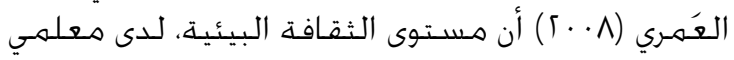

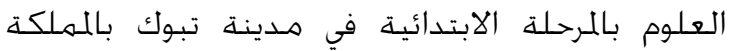

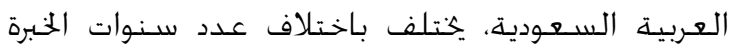
ولصالح ذوي الخبرة الطويلة. وكذلك وجـد عبد الغنـ الغني

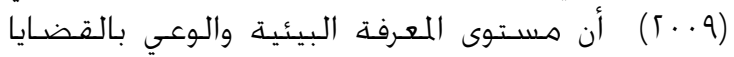

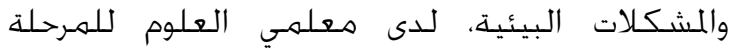

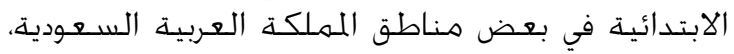

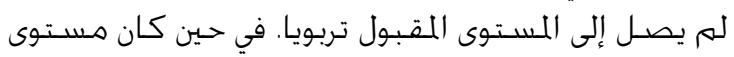

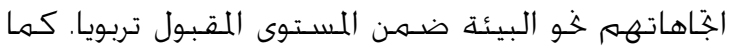

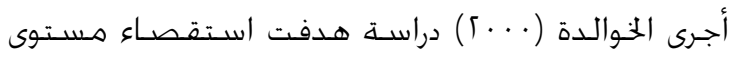

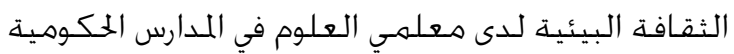

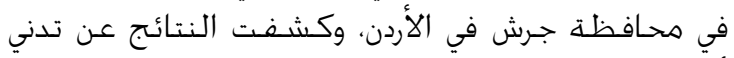

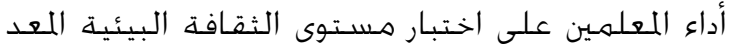
خصيصـا لذلك.

كما حاولت بعض الدراسـات استقـصـاء أثر عواهل

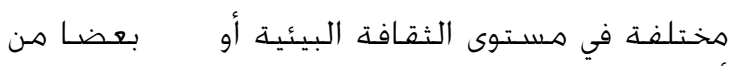

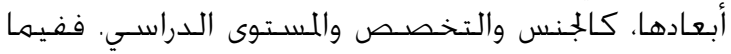

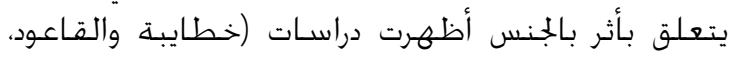
(Tikka, Kuitunen \& Tynys, 2000; Coyle, 2005; : . . . Tuncer, et al, 2009;

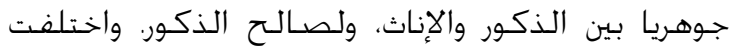

الاسـمي (Nominal): ويشير إلى قدرة الفـرد على المي

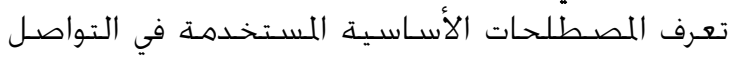

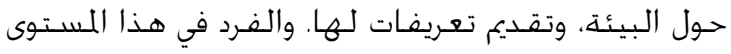

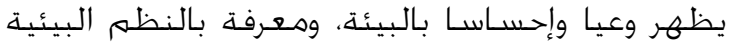
وكيفية تفاعل البشـر هعها.

الوظيفي (Functional): ويشـير إلى قـدرة الفـرد على المي

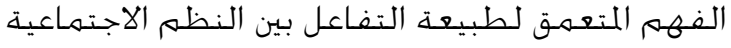

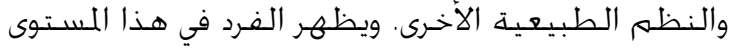

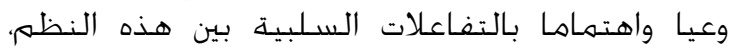

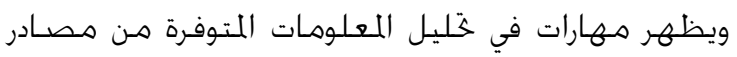

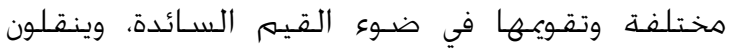
خـبراتهـم وهشـاعرهم للآخـرين.

الإجرائي (Operational): ويشـير إلى الفـرد الذي

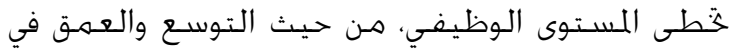

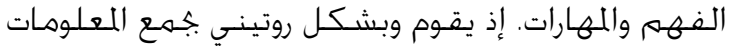

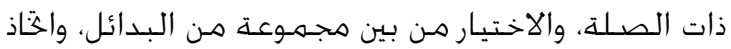

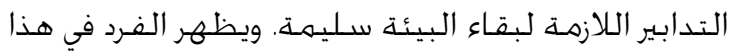

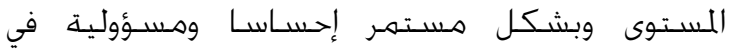

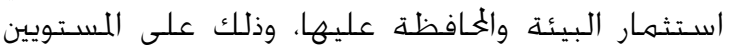
الفـردي والجـماعي.

ونظرا لأهـميـة الثقافة البئية لدى الأفراد؛ كونها

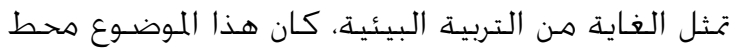

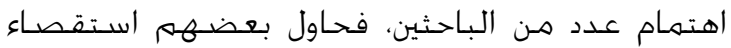

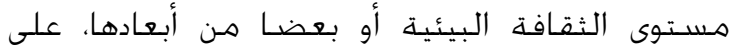

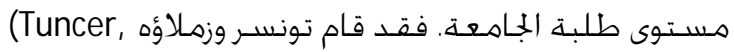
Tekkaya, Sunger, Cakiroglu, Ertepinar \& Kaplowitz, (2009 ، بدراسـة هـدفت إلى اسـتقصاء هسـوى الثقافة البيئية لدى الطلبة المعلمـين في إحسى الجامعات البـات التركية.

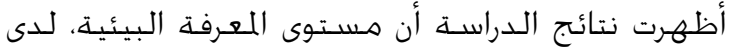

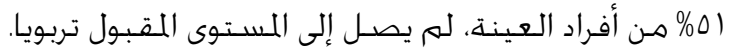

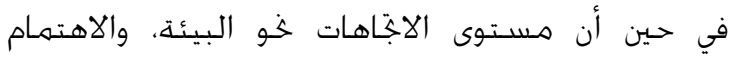

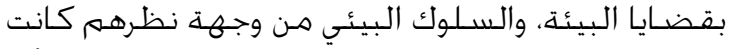

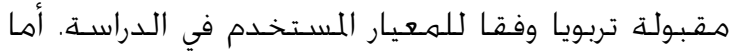

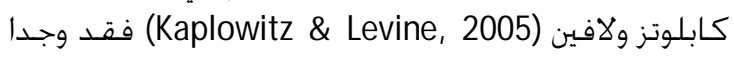

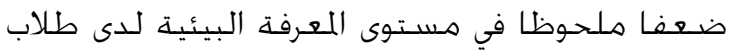

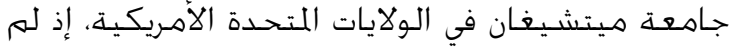

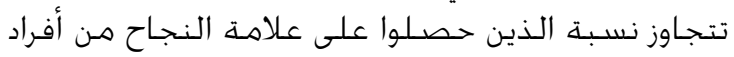

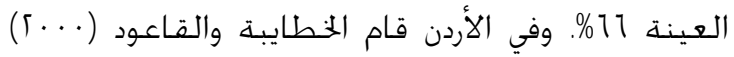

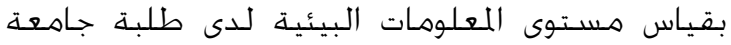

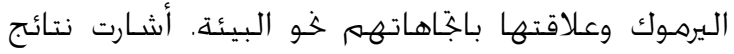

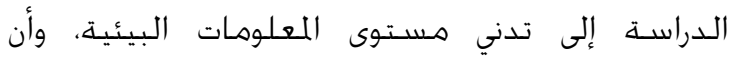

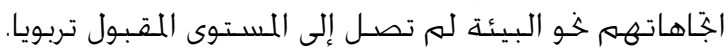

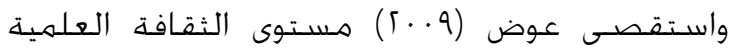

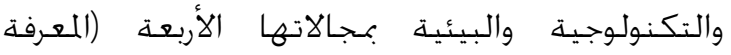

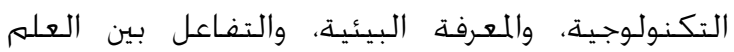


عمليات ونواتج العلم على الناس والبيئة"، و"الوعي الاسي

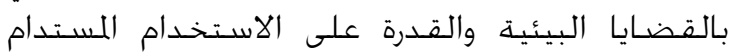

لمصادر البيئة" ( وزارة التربية والتعليم، ه . الـ، صه ).

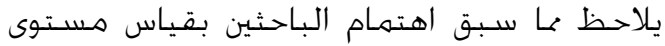

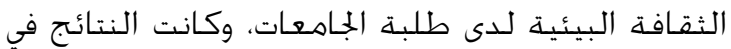

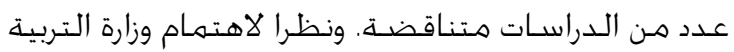

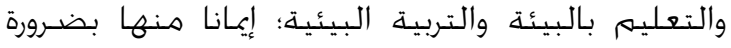

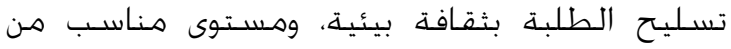

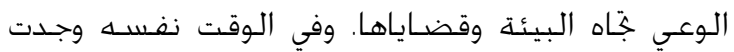

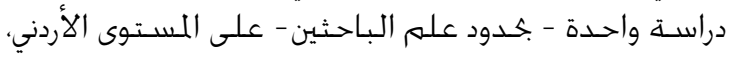

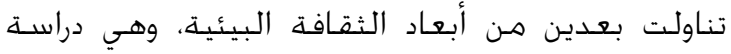

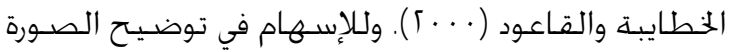

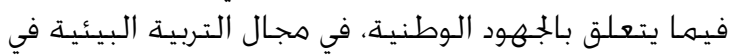

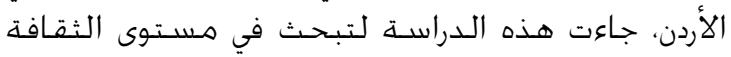

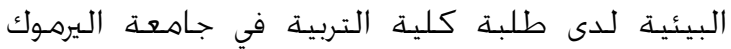
وعلاقتها ببعض المتغيرات.

\section{مشكلة الدراسة وأسئلتها:}

إن إعداد الطلبة الجامعيين المثقفين بيئيا، يعد أمرا

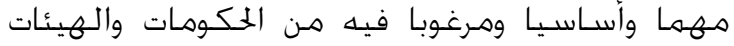

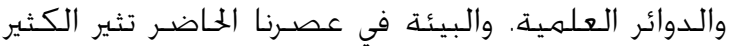

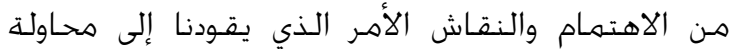

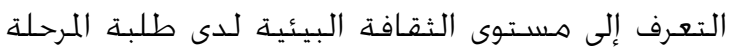

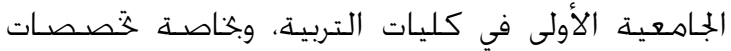

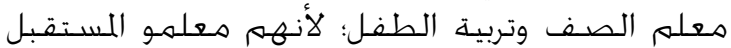

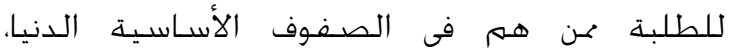

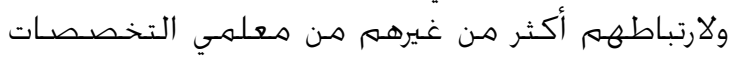

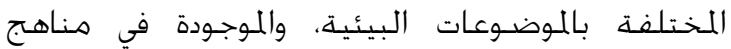

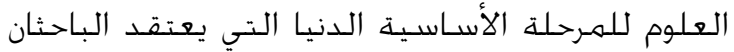

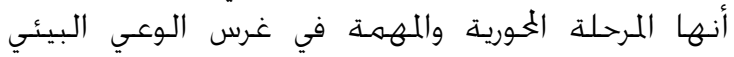

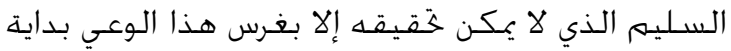

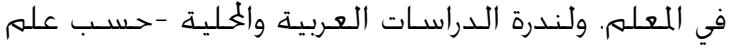

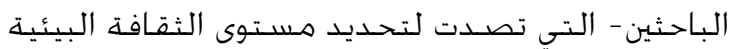

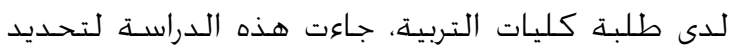

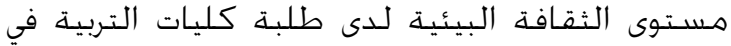
المرحلة الجامعية الأولى، وعلاقته ببعض لإئه المتغيرات. وعليه

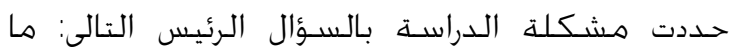

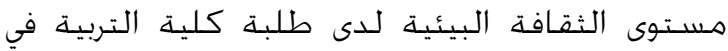

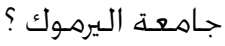

\section{أسئلة الدراسة:}

هـفتت الدراسـة إلى الإجابة عن السـؤالين الآتيين: ا - ما مسـتوى الثقافة البئيسة لدى طلبـة كليـة التربية

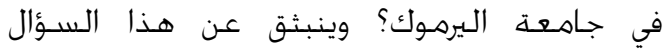
الأسـئلة الفـرعية التالية:

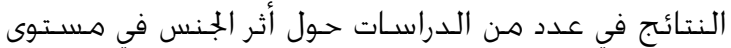

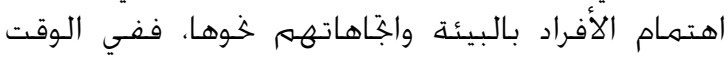

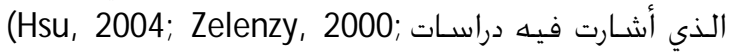
إلى أن الإناث أكثر Coyle, 2005; Tuncer, et al, 2009)

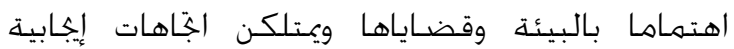

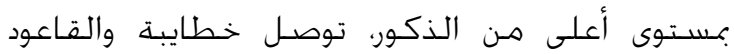

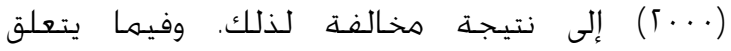

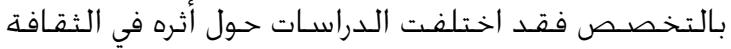

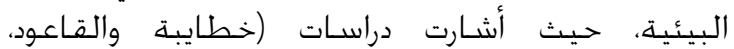

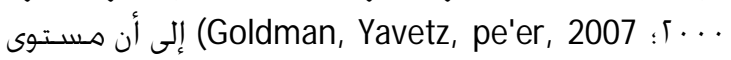

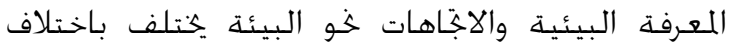

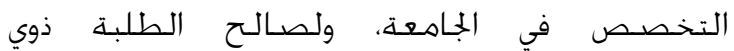

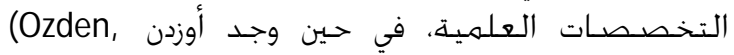

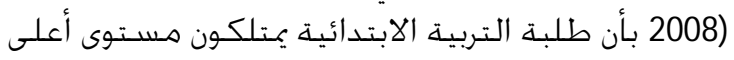

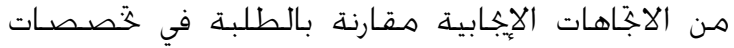

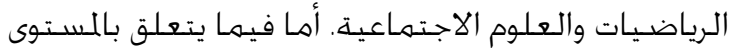

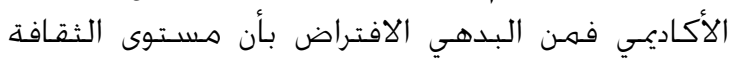

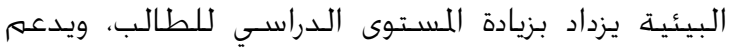

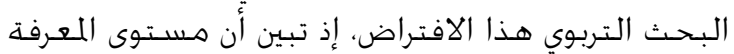

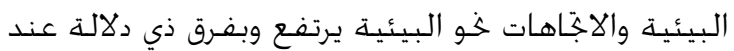

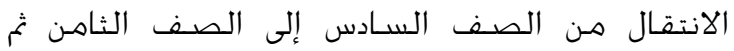

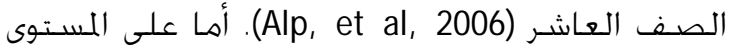

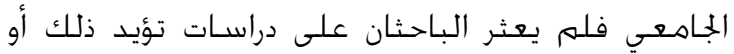

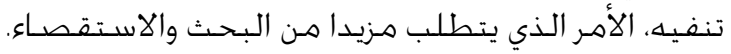
وقد حرصـت مختلف دول العالم، منذ مؤتمـر الأمسم

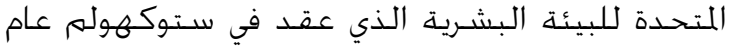
19VT

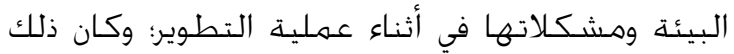

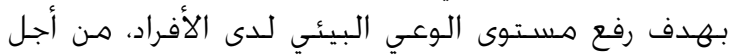

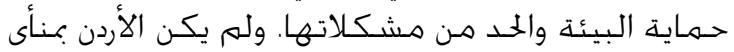

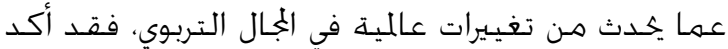

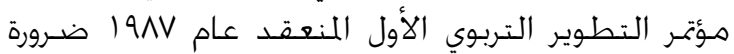

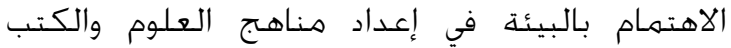

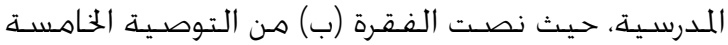

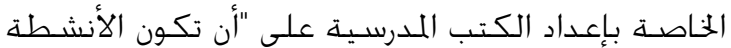

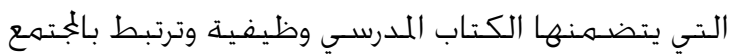

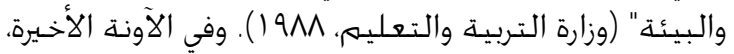

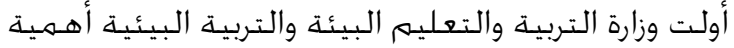

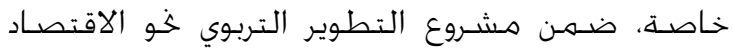
المعرفي تال Economy: EREFKE" الإطار العام في مبحـث العلوم لمرحلة التعليم الأسـاسـي.

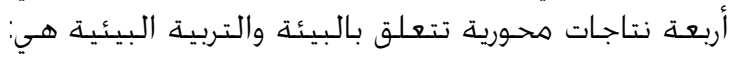

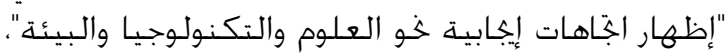
و"إدراك العـلاقات المتبادلة بين الكائنات الحية والبـات والبئة".

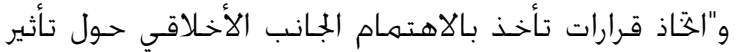


مسـتوى الثقافة البئية: يتكـون هذا المســوى هـن أربعة أبعاد هي: - ملئ

ا - اللعـرفة البئيـة: إدراك الفـرد للمفـاهيم والقضــايا

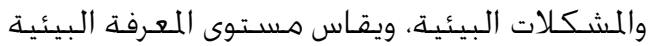

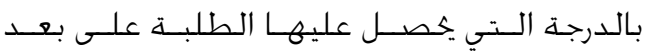
المعرفة البيئية مـن مقياس الثقافة البيئية.

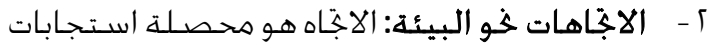

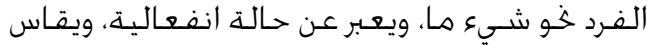

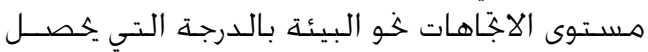

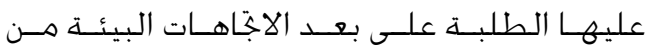
مقياس الثقـافة البيئية.

r - الممارسـة البئية: توجهـات الفـرد للمششـاركة في

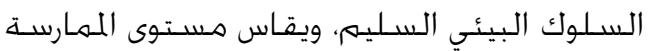

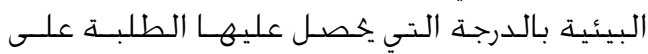
بعد الممارسـات البيئية في مقياس الثقافة البئيـة.

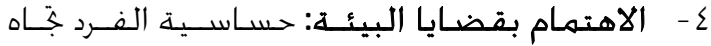

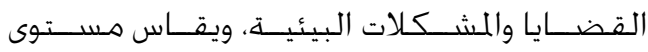

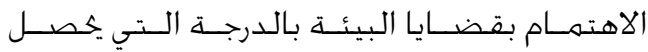

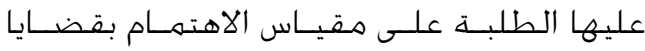
البيئة الغملية والعالمية.

طلبة كلية التربية: طلبة كلية التربية في جامعة

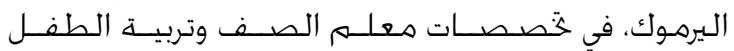

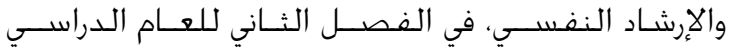
$. \Gamma \cdot 11 / \Gamma \cdot 1$.

مجتمع الدراسة وعينتها: جدول 1 توزيع أفراد عينة الدراسة حسب متغيرات الجنس، التخصص، المستوى الدراسي عنئه

\begin{tabular}{cccc}
\hline المتغير & & \\
\hline & & & \\
\hline
\end{tabular}

\begin{tabular}{|c|c|c|}
\hline$\wedge 9, r$ & 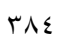 & أنثى \\
\hline rT, T & $1 \varepsilon$. & معلم صف \\
\hline
\end{tabular}

تربية طفل

\begin{tabular}{|c|c|c|c|}
\hline$r q, r$ & KT & إرشاد & \\
\hline$r, 9$ & $9 \varepsilon$ & أولى & المستوى \\
\hline r & $1 \leqslant 1$ & ثانية & الدراسي \\
\hline$r \varepsilon, \varepsilon$ & 1.0 & ثالثة & \\
\hline$r \cdot, q$ & 9. & رابعة & \\
\hline $1 \cdots$, & $\varepsilon r$. & الكلي & \\
\hline
\end{tabular}

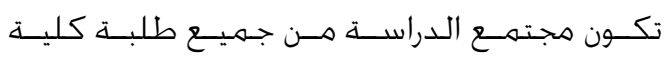

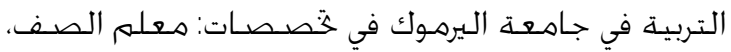

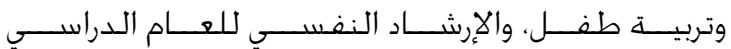

• ما مستوى اللعـرفة البيئية لدى طلبة كلية التربية

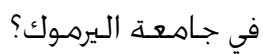
• ما مستوى الاجّاهات خون البيئة لدى طلبة كلية

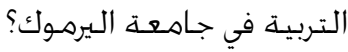

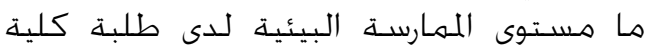

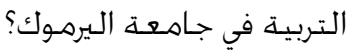

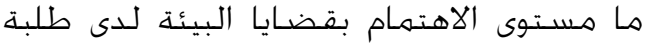

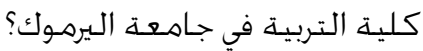
ا - هل توجـد فروق ذات دلالة إحصائية عند مسـتوى

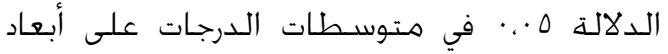

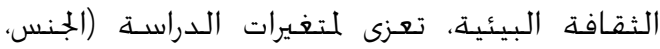

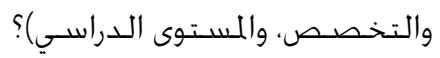

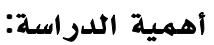

ما هـن شـك بأن للمعلملم دورا رئيسـا في غـرس القـيـم

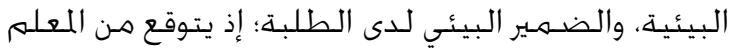

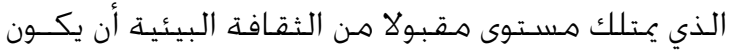

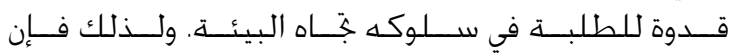

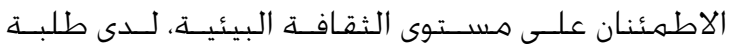

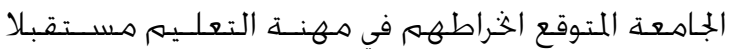

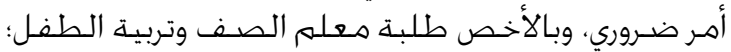

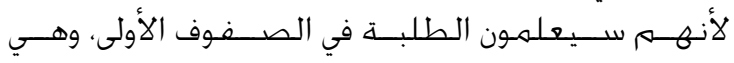
مرحلة محهورية مهـمـة في غرس السـلوك البيئي السـليهم.

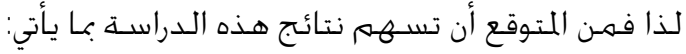

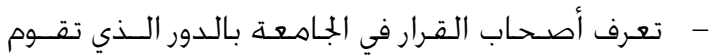

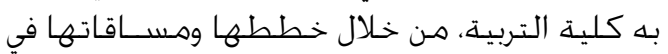
إكسـاب الطلبـة الثقافـة البيئية.

- تسياعـد أصحاب القـرار في الجامعة في الخاذ الإجـراءات

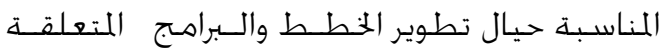

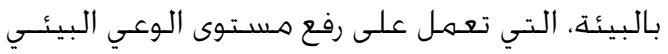
لدى الطلبـة، وإكسـابهـم السـلوك البيئي السـليهم.

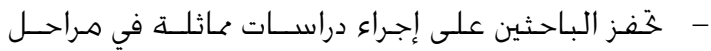
تعليميـة مختلفـة.

مصطلحات الدر اسة:

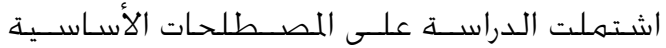
الآتية: -

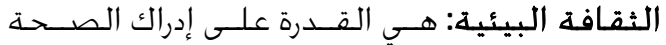

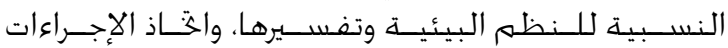

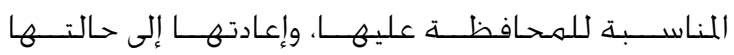

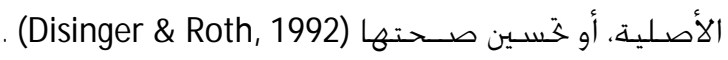

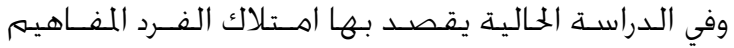

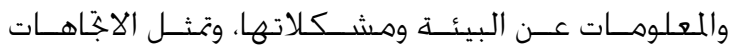

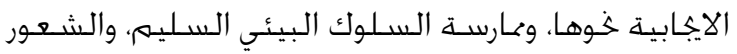

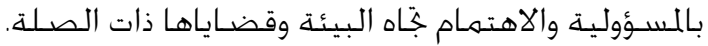




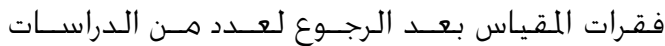

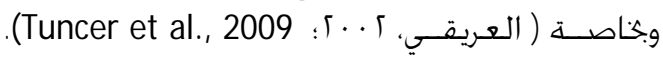

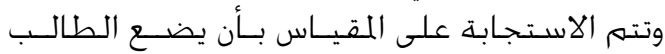

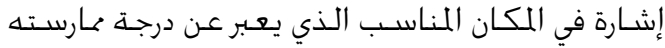

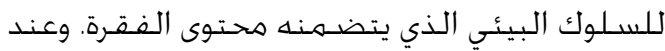

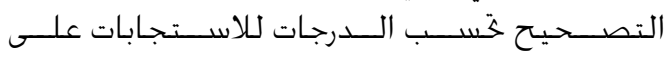

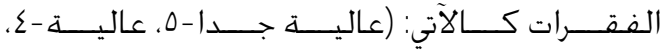

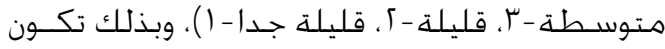

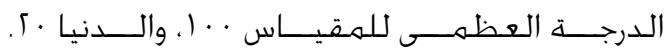

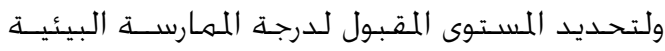

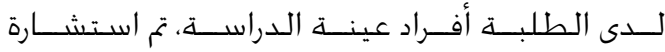

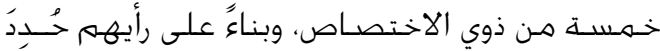

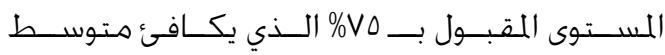

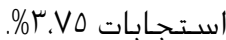

ع. مقياس الاهتمام بقضايا البيئة العلية والعالمية:

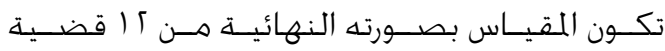

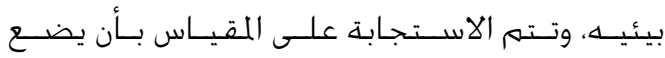

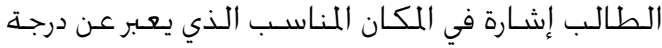

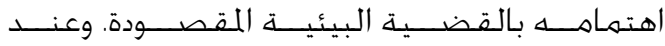

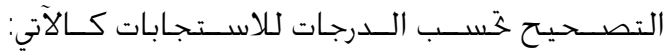

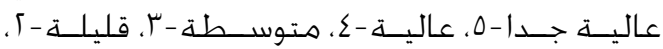

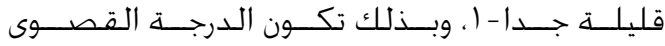

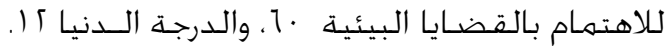

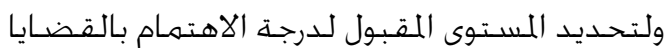

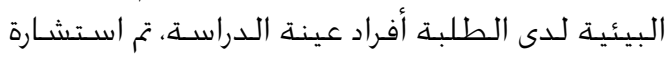

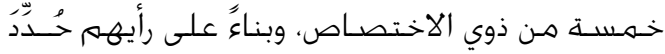

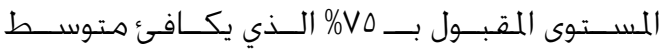

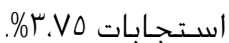

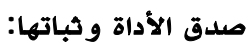
جدول ra معاملات الاتساق الداخلي وثبات الإعادة لأبعاد أداة الثقافة البيئية

\begin{tabular}{|c|c|c|c|}
\hline الفقرات & ثالإعادة & الالاخاق & المقياس \\
\hline$r$. & $\cdot, \wedge V$ & $\cdot, \vee \wedge$ & المعرفة البيئية \\
\hline r^ & •,AY & •, & الالجاهات نحو \\
\hline$r$. & • & $\cdot, \wedge 0$ & الممارسات \\
\hline rr & $\cdot, \wedge \wedge$ & $\cdot, \wedge 7$ & دمشكلات البيئة \\
\hline
\end{tabular}

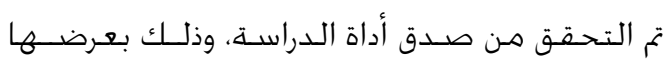

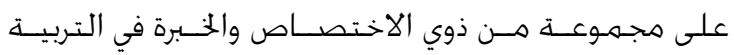

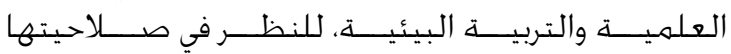

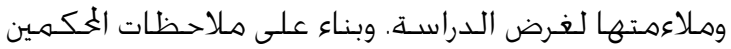

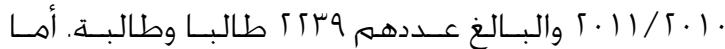

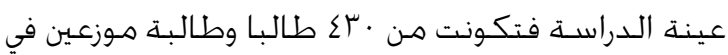

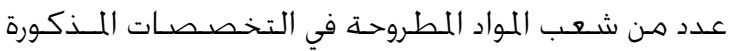

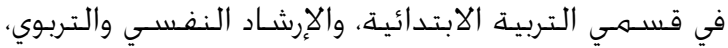

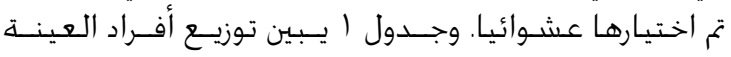

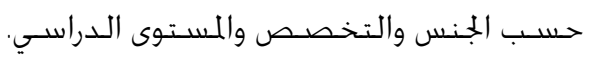

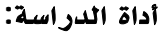

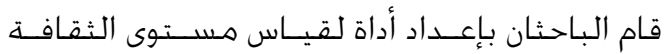

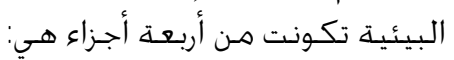

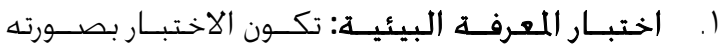

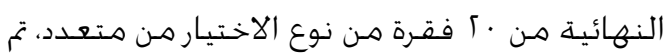

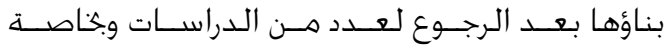
(Wright, 2008; Kaplowitz \& Levine, 2005; Morrone, Manci \& Carr, 2001

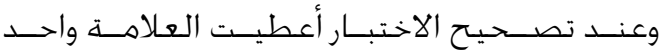

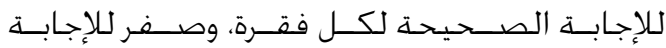

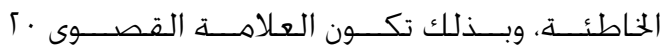

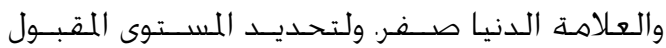

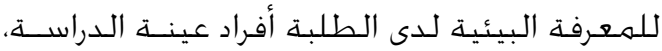

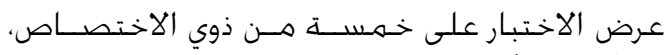

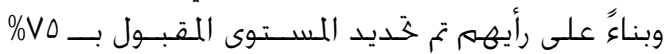
الذي يكافئ متوسط استجابات الـات العلى الاختبار. ז. مقياس الاجّاهات خو البئية: تكون المقياس بصورته

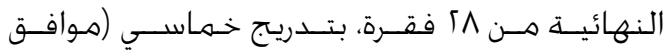

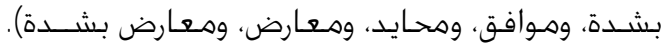

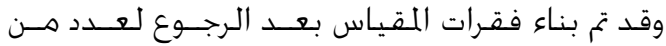

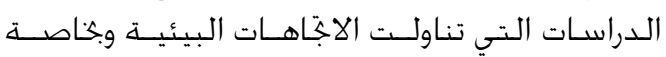

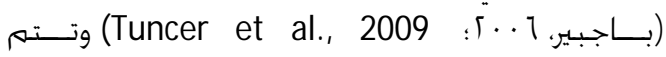
الاستجابة على المقياس بأن يضع الطالب إشـارة في

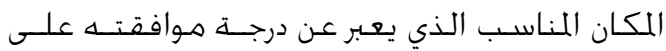

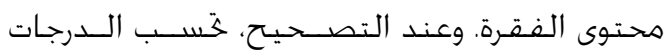

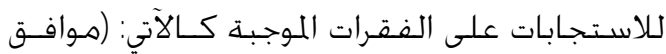

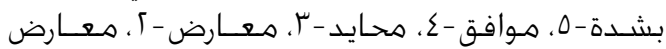

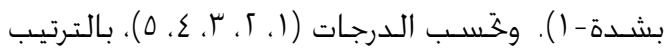

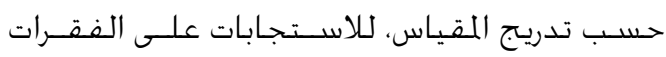

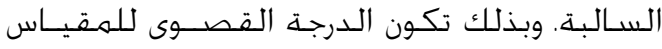

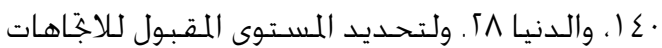

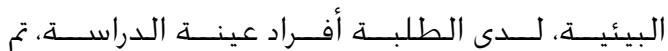

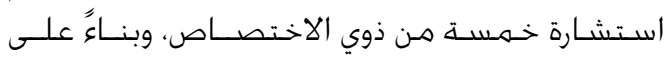

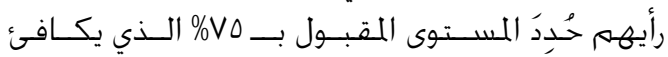

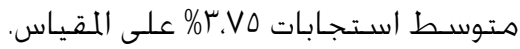

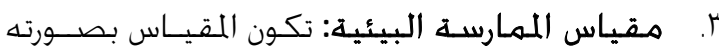

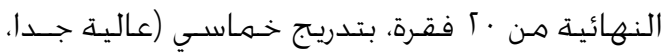

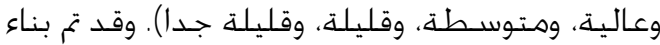




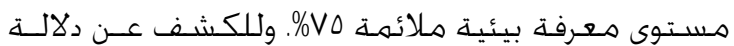

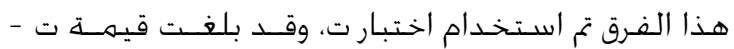

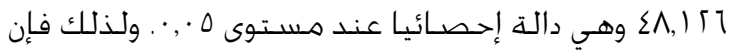

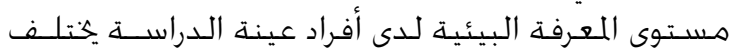

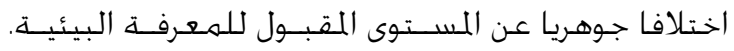

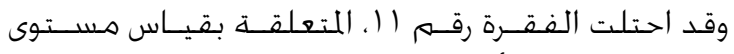

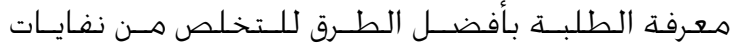
المنـازل، المرتبـة الأولى بوسـط حسبابي V19, · واخـراف مـعياري

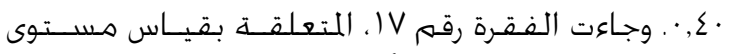

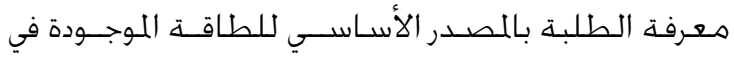

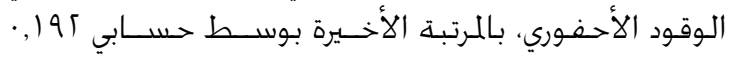

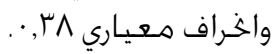
جدول r

الرتبة والمتوسط الحسابي والانحراف المعياري

لاستجابات على فقرات اختبار المعرفة البيئية

\begin{tabular}{|c|c|c|c|}
\hline الانحراف & المتوسط & رقم & \\
\hline المعياري & الحسابي & الفقرة & \\
\hline
\end{tabular}

$\cdot, \varepsilon \cdot, \vee \vee 99 \quad 11 \quad 1$

$\cdot, \varepsilon r \quad, V \leq T \quad r . \quad r$

$\cdot, \varepsilon \varepsilon \quad, V Y . \quad 0 \quad r$

$\cdot, \varepsilon \varepsilon \quad \cdot, V \cdot T \quad q \quad \varepsilon$

.,, , tos r

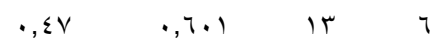

.,$\varepsilon \wedge \quad ., 0 \wedge T \quad$ l $\varepsilon \quad V$

$\cdot, \varepsilon \Lambda \quad, 0 . r \quad$ ir

$,, \leqslant q \quad,, \varepsilon \vee \leqslant \quad 1 \quad 9$

$\cdot, \varepsilon \wedge \quad, \leq 0 V \quad r \quad 1$.

$\begin{array}{llll}., 59 \quad \text {, sor } 17 & 11\end{array}$

$\cdot, \varepsilon \wedge \quad,, \varepsilon \varepsilon \varepsilon \quad$ in

ש

, $, \varepsilon \varepsilon \quad,, 490 \quad \varepsilon \quad 1 \leq$

., $\varepsilon$,, TTV 10

$\begin{array}{llll}\cdot, E & ., T \leq 1 & 10 \quad 17\end{array}$

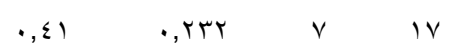

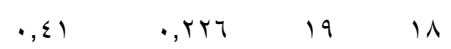

$\cdot, 19 \quad \cdot, 19 \leq \quad 1 . \quad 19$

$\begin{array}{llll}\cdot, r \Lambda & \cdot, 9 r & \text { IV }\end{array}$

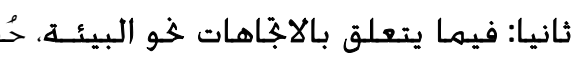

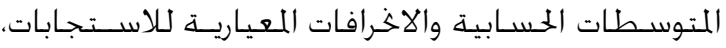

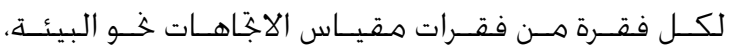

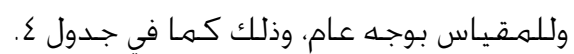

حـذفت بعض الفقـرات، وأعيــدت صــــاغـة فقـرات أخــرى.

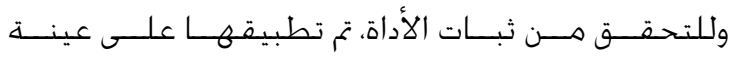

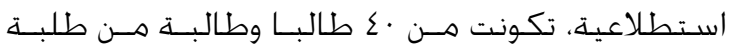
كلية التربية في جامعـة اليرهوك مـن خـارج عينة الدراسـة.

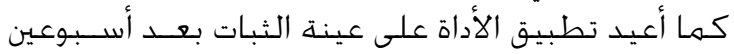

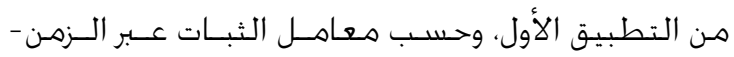

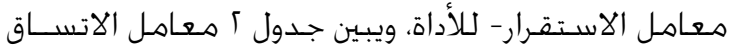

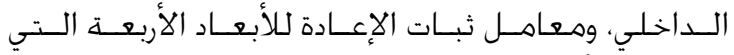

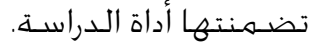

التصميم والمعالجة الاحصائية:

تعـد هذه الدراســة مــن نــوع الـدراسـات الوصــفيـة،

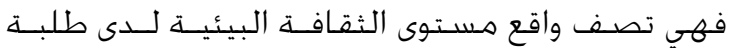

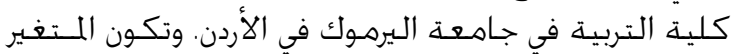

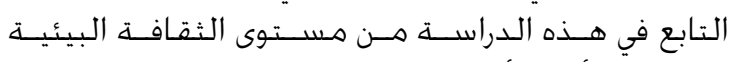

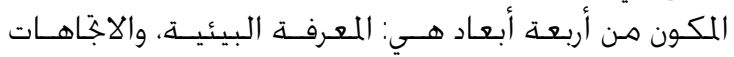

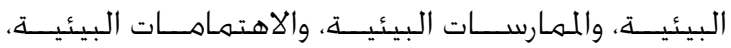
وتكونت المتغيرات المستقـلة في هذه الـراســة مـن:

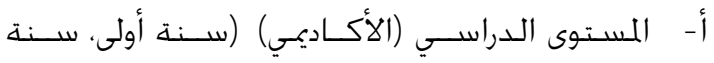
ثانية، سـنة ثالثة، وسـنة رابعة).

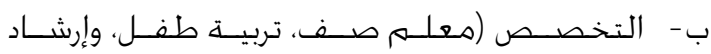
نفسـي). ج - الجنس (ذكر، وأنثى).

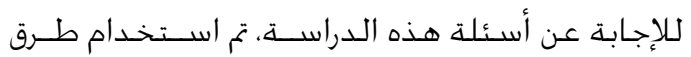

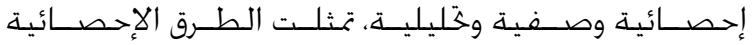

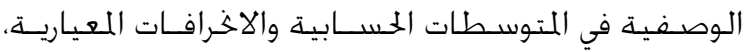

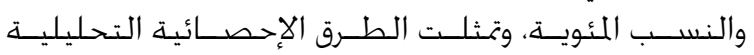

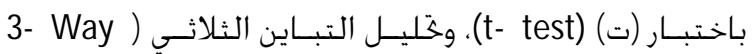
(ANOVA

\section{النتائج}

النتائج المتعلقـة بالسـؤال الأول: "ما هسـتوى الثقافة

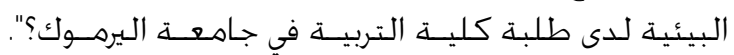

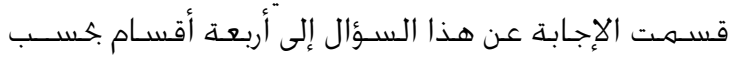
أبعاد الثقافة البيئية وهي:

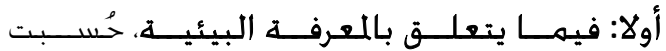

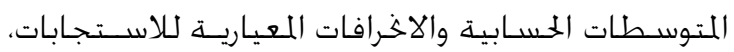

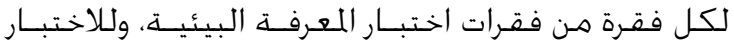

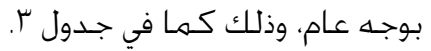

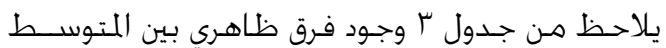

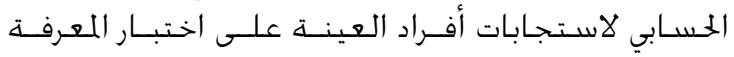

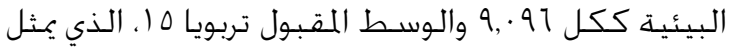


جدول ع

الرتبة والمتوسط الحسابي والانحراف المعباري للاستجابات على فقرات مقياس الاتجاهات نحو البيئة

\begin{tabular}{|c|c|c|c|c|c|}
\hline 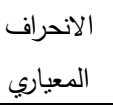 & المستوسط & مقياس الاتجاهات نحو البيئة وفقراته & الفجاه & رقمة & الرتبة \\
\hline$\cdot, \wedge r$ & $\varepsilon, 0$ OY & أشـجع وجود برامهج للتربية البيئية في جـميع المراحل التعليم & & 9 & 1 \\
\hline$\cdot, \vee \vee 9$ & $\varepsilon$, OY & أرى أن حل المشكلات البيئية مسؤولية جماعية & & rV & r \\
\hline$\cdot, \wedge \varepsilon$ & $\varepsilon, \varepsilon \vee q$ & أرى أن إدراك مشـكلات البيئة من قبل جـميع أفراد الجُــمع أهر مهـم & & r & r \\
\hline • & $\varepsilon$, rYA & أشجحع فرض غرامات على المواطنين الذين يرهون النفايات في غير أماكنها & & 17 & $\varepsilon$ \\
\hline$\cdot, \wedge \wedge$ & $\varepsilon, r \vee q$ & أرى أن من واجب الدولة أن تنظم استعمالات الأراضي لحماية البيئة & & $r \varepsilon$ & ○ \\
\hline $1, \cdot 1$ & $\varepsilon, r_{\cdots}$ & يزعجنـي خويل الأراضـي الزراعبة إلى عمارات وشـوارع معبدة & & 1 & 7 \\
\hline$\cdot, \wedge \varepsilon$ & $\varepsilon, 1 Y \wedge$ & أرى أن تغيير الأنماط الاستهلاكية يسـاهم في حل المشكلات البيئية & & rی & v \\
\hline $1, .0$ & $\varepsilon, \cdot \wedge \varepsilon$ & أشعر بالضـق من الأفراد الذين يقطعون الأشجـار لاستخـدامها في التدفئة شـاءً & & r & $\wedge$ \\
\hline$\cdot, 90$ & $\varepsilon, .01$ & أرى أن من واجب الدولة أن تضع قوانين جَعل إعادة التدوير إلزاميا & & ro & 9 \\
\hline$\cdot, 94$ & $r, 9 \wedge 1$ & أرى أن موارد البيئة كافية إذا تعلمنا كيفية تطويرها & & 19 & 1. \\
\hline $1, \cdot \varepsilon$ & $r, q \cdot v$ & أرى أن حل المشكلات البيئية يتطلب تغييرا في العتقـدات والقيم لدى الأفراد & & ז & 11 \\
\hline $1, \cdot 1$ & $r, v \cdots$ & أؤيد استعمال المبيدات العشبية للقضـاء على الأعشاب الضـارة & عكسية & r & ir \\
\hline 1,11 & $r, T V V$ & يسعدني منع استخــام البنزين الخالي من الرصـاص في محـركات السيارات & & 1 & ir \\
\hline$\cdot, 90$ & $r$, rی & أعتقـد أننا نقترب من الحــ الأعلى من السـكان الذي تستـيع الأرض أن تسـتوعبه & & 11 & $1 \varepsilon$ \\
\hline 1,11 & $r, r \vee v$ & أعتقـــ أن من حق الأفراد اسـتعمال أراضـيهـم بالشـكل الذي يرونه مناسبا & عكسية & r) & 10 \\
\hline $1, r$ & $r, r .0$ & أعتقد أن مـن حق المزارعين اســعمال المياه للأغراض الزراعية بالشكل الذي يرونه مناس & عكسية & rt & 17 \\
\hline $1, r \varepsilon$ & $r, \cdot \wedge r$ & أرى أن الاستـخدام الكثثف للأســدة ضـرورة لتحسـين نوعية التربة وزيادة الانتاج & عكسية & $1 \leqslant$ & iv \\
\hline $1, \cdot 1$ & r.० & أعتقد أن العلماء يبالغون في توقعاتهم للأزمات البيئية المرتقب حدوثها & عكسية & iv & 11 \\
\hline $1, r V$ & r,OVY & أوافق على خَصيص ضريبة إضـافية على الهاتف الخلوي لإنشـاء محهـيات طبيعية & & 11 & 19 \\
\hline $1,1 \mathrm{~V}$ & $r, 0 \leqslant \varepsilon$ & أرى أن قتل الحيوانات المفترسـة ضـرورة للحفـاظ على الحيوانات الأليفة & عكسية & $\varepsilon$ & r. \\
\hline $1, .9$ & 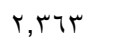 & 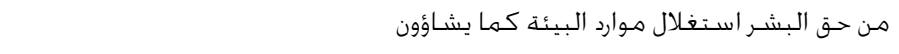 & عكسية & r. & (1) \\
\hline $1, \mathrm{r} \wedge$ & $r, r \leq \varepsilon$ & أتفق مع الحكومة عند رفع قيمة فاتورة الكهرباء لأن ذلك يحافظ على الطاقة & & $\wedge$ & rt \\
\hline 1,14 & $r, .91$ & أعتقد أن الخوف على الموارد الطبيعية مبالغ فيه لأنها متوفرة بكثرة & عكسية & 0 & rt \\
\hline $1, \cdot \varepsilon$ & $1,97 V$ & التوازن البيئي التوازن البيئي لا يدعو للقلق فـالعلم والتكنولوجيا كفيلان بحل المشكلات وإعادة & عكسية & ir & $r \leq$ \\
\hline $1, \cdots$ & l, AVV & أعتقـد أن التربية البيئية غير ضـرورية في المجتمعات التي لا تعاني من مشكلات بيئية & عكسية & $1 \cdot$ & ro \\
\hline I, r & $1, \wedge \vee V$ & تضـايقنـي المناداة بترشيد اســهلاك المياه لأن ذلك يمثل تدخلا في حرية الأفراد & عكسية & v & ז \\
\hline $1,1 \mathrm{r}$ & $1, \wedge \vee \varepsilon$ & أرى أن حماية البيئة مسؤولية الدولة وليس الأفراد العاديين & 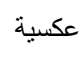 & ir & rv \\
\hline$\cdot, \wedge \varepsilon$ & 1,rro & أشـجع إقامة المصانع بالقرب من المناطق السكنية & عكسية & 10 & rی \\
\hline$\cdot, r \cdot$ & $r, r / 9$ & 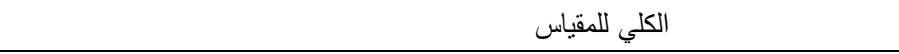 & & & \\
\hline
\end{tabular}

المناطق السـكنيـة" بالمرتبـة الأخـيرة بوسـط حســابي هسّر,

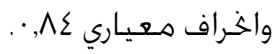

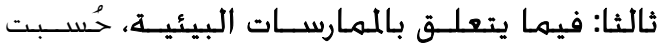

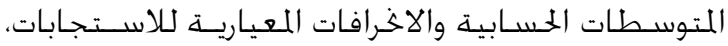

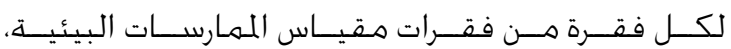

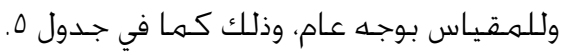

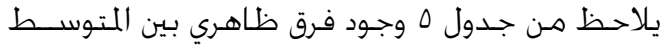

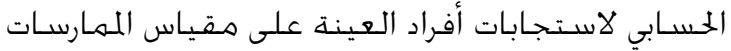

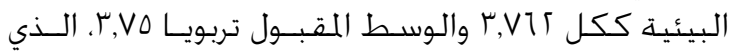

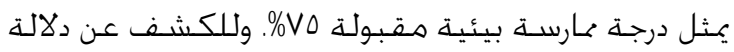

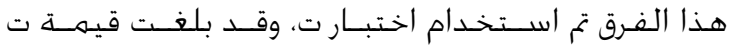

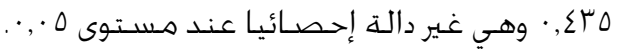

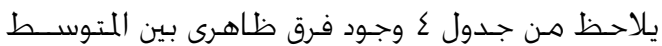

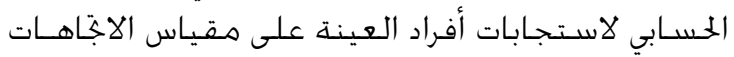

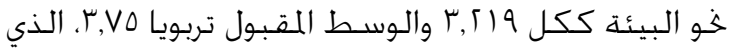

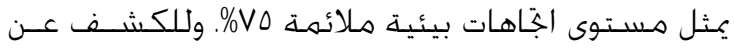

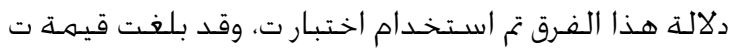
1, rVV-

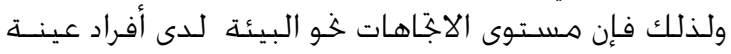

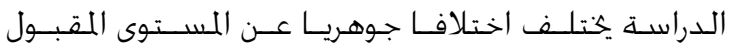

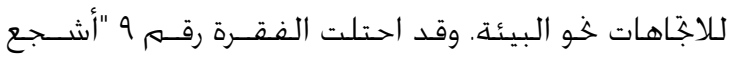

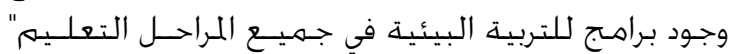

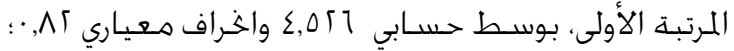

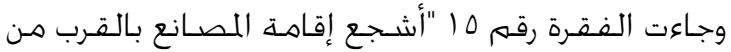


جدول

الرتبة والمنوسط الحسابي والانحراف المعياري للاستجابات على فقرات مقياس الممارسات البيئية

\begin{tabular}{|c|c|c|c|c|}
\hline الالمعراف & الحسابي & مقياس الممارسات البيئية وفقراته & 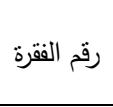 & الرتبة \\
\hline$\cdot, \mathrm{VY}$ & $\varepsilon, 0 Y 1$ & احرص على ترك الأماكن الترفيهية نظيفة عند زيارتها & 1 & 1 \\
\hline$\cdot$, , & $\varepsilon, \varepsilon \vee$. & ألتزم بإلقاء النفايات في أماكنها المخصصـة & r & r \\
\hline $1, \cdot 1$ & $\varepsilon, \Upsilon 9 \wedge$ & أحسرص على عدم إيذاء الناس عند استخـــامي للخـلوي & r. & r \\
\hline$\cdot, \wedge 0$ & $\varepsilon, r \vee V$ & أحافظ على اللظهر الجمالي للأماكن العامة & 1. & $\varepsilon$ \\
\hline$\cdot, 91$ & $\varepsilon, Y_{Y}$ & استخـدم أكياس للنفايات عند خروجي في رحلات & iv & $\circ$ \\
\hline $1, \cdot \wedge$ & $\varepsilon, r \cdot r$ & أمتنع عن إلقاء النفايات من نوافذ السيارات & 17 & 1 \\
\hline$\cdot, 94$ & זער & أغلق المصابيح والأجهزة الكهربائية بعد استخـدامها مباشـرة & 9 & v \\
\hline$\cdot, 90$ & $\varepsilon, 1\}$ & أعرض عن ممارسـة الأنشطة التي تؤذي النباتات والحيواتان & ○ & $\wedge$ \\
\hline 1,14 & $\varepsilon, \cdot r_{0}$ & أحرص على استخدام وسـائل النقل العامة (الباصـات) & $\wedge$ & 9 \\
\hline$\cdot, 91$ & $\varepsilon, \ldots v$ & ألتزم بتطبيق القواعد الصــية السـليمة في حياتي & r & 1. \\
\hline 1,10 & $r, 901$ & أشجـع إقامة مصـانع خاصـة لتدوير المخلفـات & v & 11 \\
\hline$\cdot, 99$ & $r, \wedge, \uparrow$ & أبتعد عن ممارسـة الأنماط الإستهلاكية المسرفة & $\varepsilon$ & IT \\
\hline 1,14 & $r, \vee \backslash 7$ & عند شـرائي لجهاز كهربائي جـديد أحرص على أن يكون استهـلاكه للطاقة قليل & 19 & ir \\
\hline $1, \cdot r$ & $r, v \cdot 0$ & 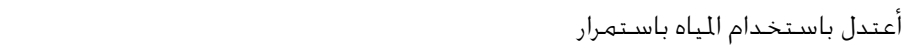 & 1 & $1 \leq$ \\
\hline 1,r & 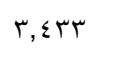 & أشـارك في توعية الناس إلى عدم قطع الشـجار واستخـدامها كوقود & r & 10 \\
\hline $1, \varepsilon$. & $r, r .0$ & أرغب في المشـاركة بغرس الأشجار في يوم عيد الشـجرة ل & 11 & 17 \\
\hline $1, r 7$ & r, १דV & أحرص على متابعة البرامج التلفزيونية التي تتناول البيئة ومشـكلاتها & $1 \leq$ & iv \\
\hline 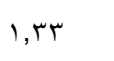 & r,^or & أحرص على استخـدام الزجاجات المسترجعة عند الرغبة في شـرب العصائر والمرطبات & ir & 11 \\
\hline 1, ro & אשrד & أشـارك من خـلال وسـائل الاعلام بتوعية الناس بقضـايا البيئة & 11 & 19 \\
\hline $1, r 9$ & $r, 0 \leqslant$ & أفضـل استخـام الأطعمة المعلبة، لأنها أسهـل وأقل تكلفة من خَضـير الطعام في المنزل & 10 & r. \\
\hline$\cdot, \mathrm{OV}$ & r,VTt & 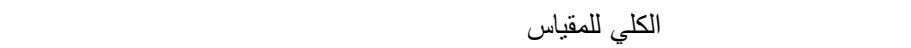 & & \\
\hline
\end{tabular}

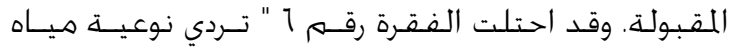

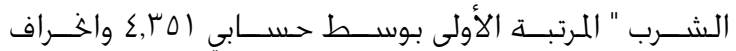

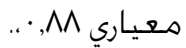

جدول 1

الرنبة والمنوسط الحسابي والانحراف المعياري للاستجابات على فقرات مقياس الاهتمام بقضايا البيئة

\begin{tabular}{|c|c|c|c|c|}
\hline الانحراف & الحسابي & مقياس درجة الاهتمام & رقف & 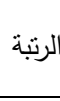 \\
\hline$\cdot, \wedge \wedge$ & $\varepsilon, \Gamma 01$ & تردي نوعية مياه الثرب & 7 & 1 \\
\hline$\cdot, \wedge 4$ & $\varepsilon, .07$ & التلوث بالدخان & 1 & r \\
\hline $1, \ldots$ & $r, 991$ & رتقاع درجة حرارة الأرض & 11 & r \\
\hline $1, \cdot \varepsilon$ & $r, 9 \wedge \tau$ & النفايات الخطرة & 0 & $\varepsilon$ \\
\hline$\cdot, 91$ & $r, q .0$ & التلوث الضوضائي & r & 0 \\
\hline •, 9 r & r,Av. & الانبعاثات من السيارات & r & 7 \\
\hline$\cdot, 9 \wedge$ & r,vro & تدمير الغابات & v & v \\
\hline $1, r r$ & r,VYT & التلوث بالإشعاعات النووية & IT & $\wedge$ \\
\hline $1, \cdot 7$ & 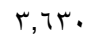 & نقص الطاقة & 9 & 9 \\
\hline $1,1 \mathrm{~V}$ & $r, 7.0$ & اضححلد (تآكل) الأوزون & 1. & 1. \\
\hline $1, \cdot 9$ & $r, \varepsilon v \varepsilon$ & التلوث الصناعي & $\varepsilon$ & 11 \\
\hline $1,1 r$ & $r, 1 \leq 9$ & خسارة النتوع الحيوي & $\wedge$ & IT \\
\hline$\cdot, T \leqslant$ & $r, v q$. & ل لي للمقياس & & \\
\hline
\end{tabular}

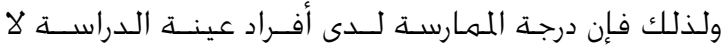

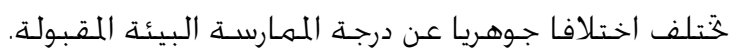

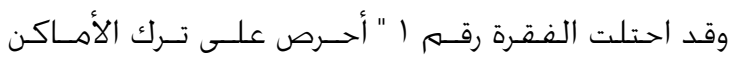

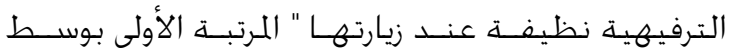

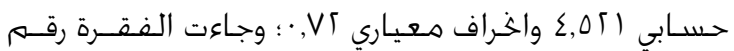

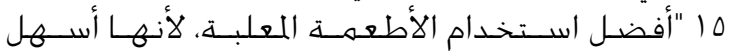

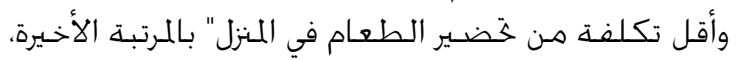

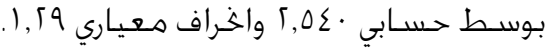

\section{رابعا: - فيما يتعلق بدرجــة الاهتمــام بالقضــايا}

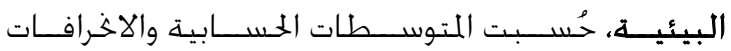

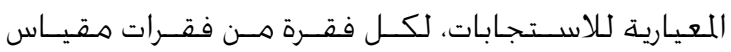

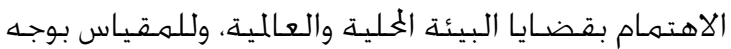
عام، وذلك كمها في جـدول 1.

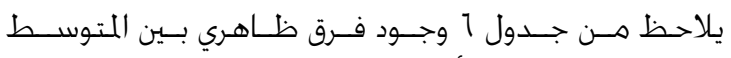

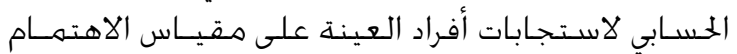

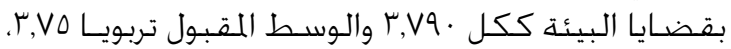

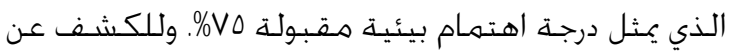

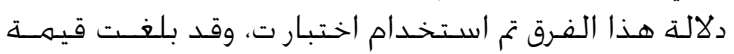

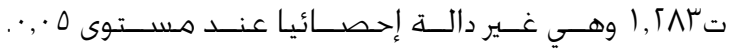

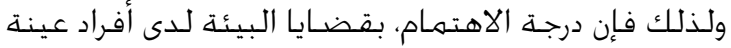

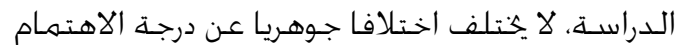


الجنس، التخصـص، المستـوى الدراسي وذلك كما في جدول

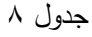

المتوسط الحسابي والانحراف المعياري للاستجابات على اختبار المعرفة البيئية وفقالمتغيرات الجنس، التخصص، المستوى الدراسي

\begin{tabular}{|c|c|c|c|}
\hline الانحراف & المتوسط الحسابي & المستويات & المتنغيرات \\
\hline r,Ir & $\Lambda, \Gamma \circ \leqslant$ & ذ كر & الجنس الجن \\
\hline$r, 0 \wedge$ & 9,110 & أنثى & \\
\hline$r, Y)$ & $9, \ldots 0$ & معلم صف & التخصص \\
\hline r, rA & $9,10 r$ & تربية طفل & \\
\hline$r, 09$ & Q,I Tr & إرشاد & \\
\hline r,0T & ת & أولى & المستوى \\
\hline$r, 79$ & $\Lambda, \wedge \wedge r$ & ثانية & الدراسي \\
\hline$r, 09$ & $9, \leqslant$ ए० & ثالثة & \\
\hline$r, r_{1}$ & $\wedge, 99 \vee$ & رابعة & \\
\hline
\end{tabular}

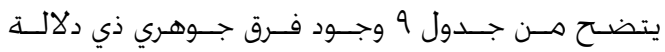

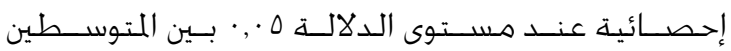

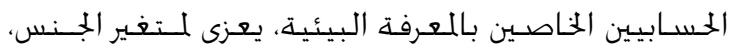

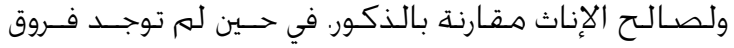

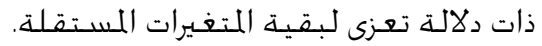

\section{جدول 9}

تحليل التباين الثلاثي للاستجابات على اختبار المعرفة البيئية وفقا

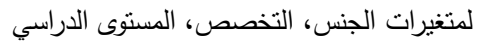

\begin{tabular}{|c|c|c|c|c|c|}
\hline الإحصائية & قيمة ف & متوسط & الدرجة & المربعوات & مصندر \\
\hline o & $\sum, \sum T Y$ & $Y \wedge, \vee \circ \Lambda$ & 1 & $r \wedge, \vee \circ \Lambda$ & الجنس \\
\hline דזה, & $\cdot, 1$. & 1,101 & r & r,T,T & التخصص \\
\hline \multirow[t]{3}{*}{ r } & $\cdot, \lambda 0 \mathrm{~V}$ & 0, oro & $r$ & $17,0 \vee 0$ & المستوى \\
\hline & & $7, \leq \leqslant 7$ & 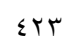 & YVYT, $\Sigma V \varepsilon$ & الخطأ \\
\hline & & & $\leqslant r q$ & $r V \vee 0, V \leq r$ & الكلي \\
\hline
\end{tabular}

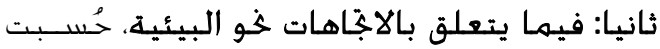

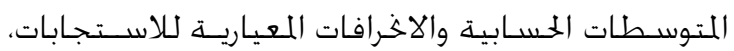

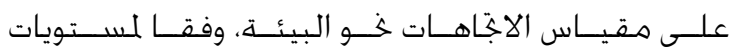

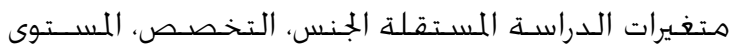

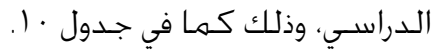

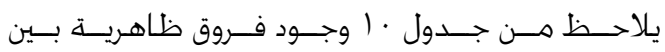

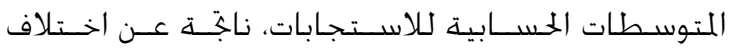

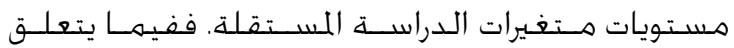

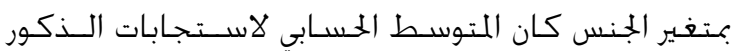

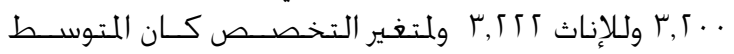

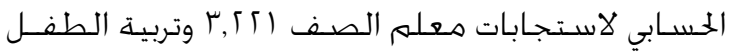

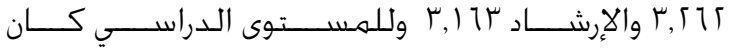

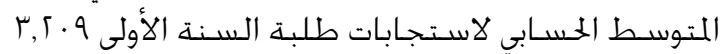

فيـــا جـاءت الفقـــرة رقــم ^ " خســـارة التـــوع الخيــوي

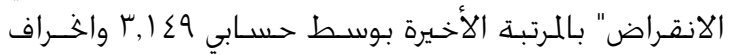

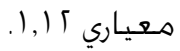

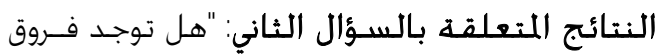

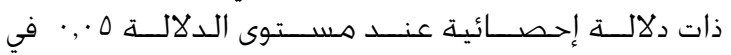

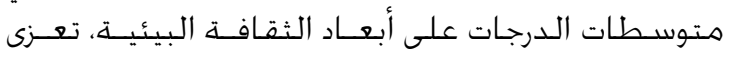

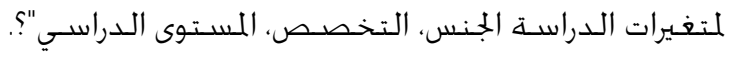
نظرا لوجود أكثر مـن مـــغير تـابع المعرفــة البيئيـة،

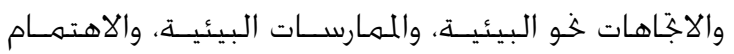

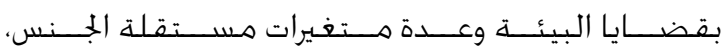

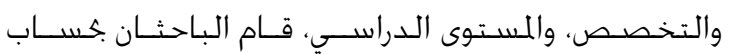

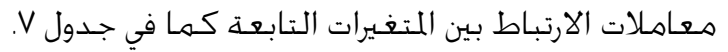

$$
\text { جدول }
$$

\begin{tabular}{|c|c|c|c|}
\hline الممارسات & الاتجاهات & المعرفة & المتغيرات \\
\hline البيئية & & البيئية & \\
\hline & & & الاتجاهات \\
\hline & & . & نحو البيئة \\
\hline & 7, & $\cdot, \cdot V$ & الممارسات \\
\hline & & & البيئية \\
\hline & & & درجة \\
\hline \multirow[t]{2}{*}{$\cdot, \cdot r$} & $\cdot, \cdots$ & $\cdot, \cdot r-$ & الاهتمام \\
\hline & & & بقضايا البيئة \\
\hline
\end{tabular}

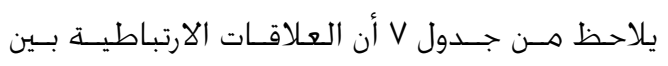

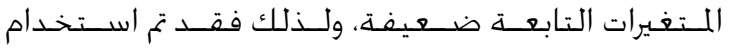

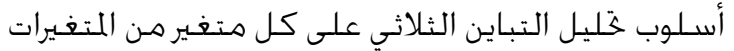

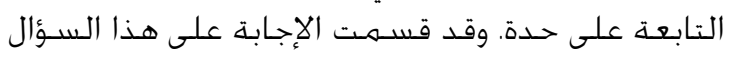
في أربعـة أقسـام جـسـب أبعاد الثقافـة البيئية كمها يلي:

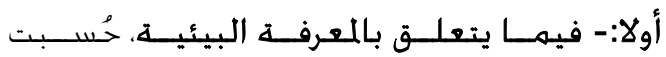

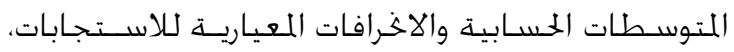

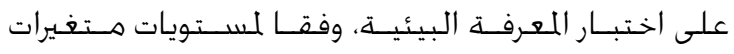

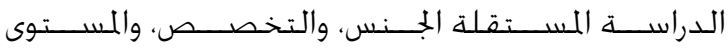

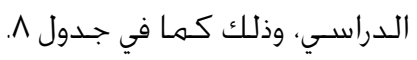

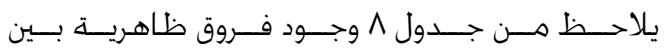

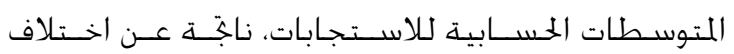

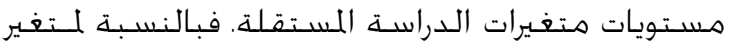

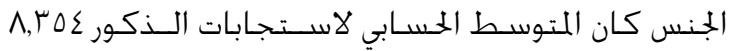

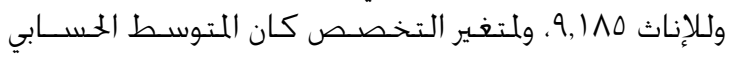

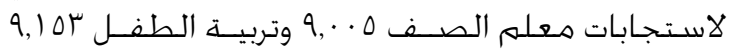

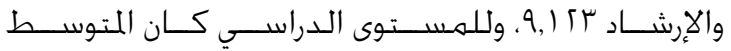

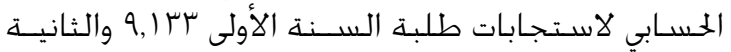

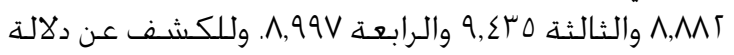

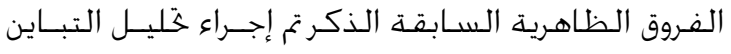

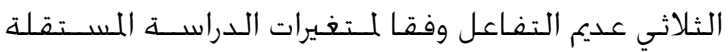


جدول

المقارنات البعدية بين متوسطات الاستجابات على مقياس الاتجاهات نحو البيئة وفقا لمستويات منغير التخصص

\begin{tabular}{|c|c|c|c|c|}
\hline تربية & معلم & إرشاد & & التخصص \\
\hline \multirow[t]{4}{*}{ r,YTr } & $r, Y Y I$ & rד & المتوسط & شافييه \\
\hline & & & זד ו,י & إرشاد \\
\hline & &., $.0 \mathrm{~V}$ & $r, Y Y I$ & معلم صف \\
\hline & $\cdot, \cdot \leq 1$ & $\cdot, .91$ & rד, r & تربية طفل \\
\hline
\end{tabular}

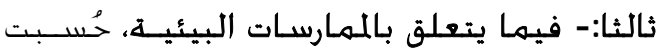

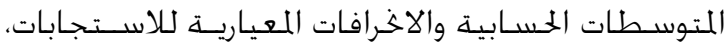

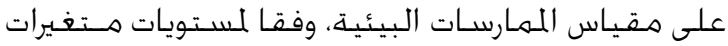

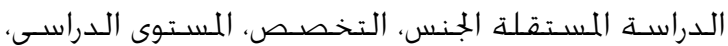

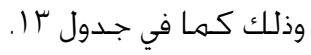

جدول rا

المتوسط الحسابي والانحراف المعياري للاستجابات على لماتى

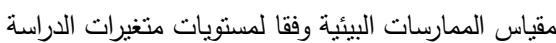

\begin{tabular}{|c|c|c|c|}
\hline الانحراف & الحسابي & المستويات & المستقلة \\
\hline$\cdot$, , 0 & $r, O V Y$ & ذكر & الجنس \\
\hline$\cdot, 0 \leq$ & r,v^o & أنثى & \\
\hline., 07 & ו וח, & معلم صف & التخصص \\
\hline$\cdot, 07$ & $r, \wedge \cdot \varepsilon$ & تربية طفل & \\
\hline$\cdot, 07$ & וזד,ז & إرشاد & \\
\hline • & $r, v V \varepsilon$ & أولى & المسنوى \\
\hline, 0 . & 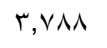 & ثانية & الدراسي \\
\hline., 00 & r,tvo & ثالثة & \\
\hline$\cdot, 09$ & $r, \wedge \cdot q$ & رابعة & \\
\hline
\end{tabular}

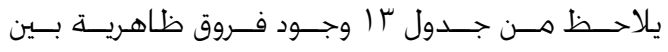

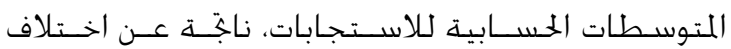

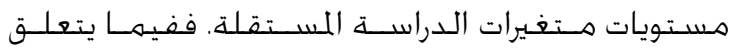

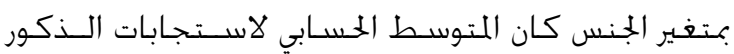

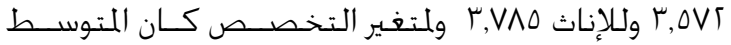

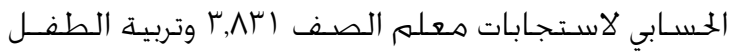

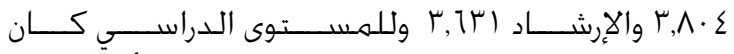

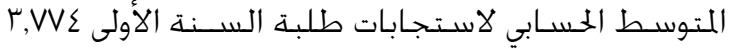

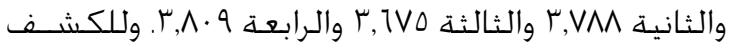

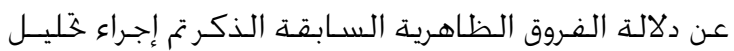

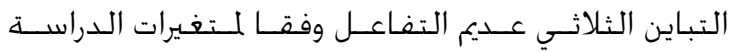

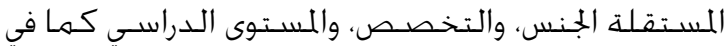

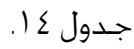

$$
\text { جدول 1. }
$$

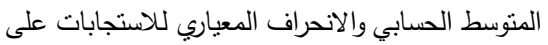

مقياس الاتجاهات نحو البيئة وفقا لمتغيرات الجنس،

\begin{tabular}{|c|c|c|c|}
\hline \multicolumn{4}{|c|}{ التخصص، المستوى الدراسي } \\
\hline الانحراف & الحسابي & المستويات & المستقلة \\
\hline • r. & $r, r \ldots$ & ذكر & الجنس \\
\hline$\cdot, r$. & T,YYT & أنثى & \\
\hline$\cdot, r$ & r,YYI & & التخصص \\
\hline$\cdot, r$. & T,YTH & تربية طفل & \\
\hline$\cdot, \Gamma$ & זד ו, ז & إرشاد & \\
\hline • & $r, r \cdot q$ & أولى & المستوى \\
\hline • & r,Yo. & ثانية & الدراسي \\
\hline • & $r, Y \cdot 1$ & ثنالثة & \\
\hline$\cdot, 19$ & $r, r \cdot \varepsilon$ & رابعة & \\
\hline
\end{tabular}

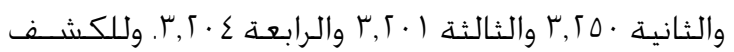

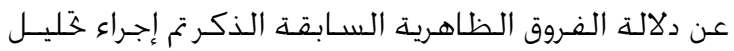

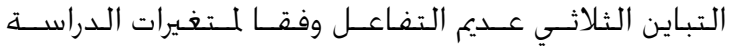

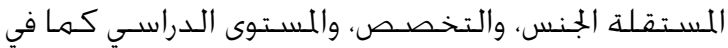

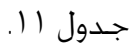

يتضـح من جـدول || (إعدم وجـود فـروق جوهـريــة ذات

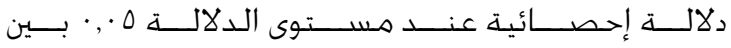

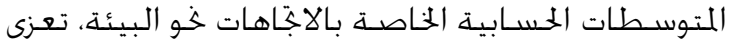

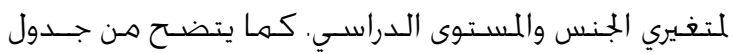

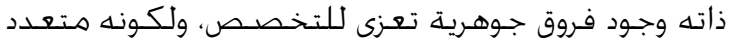

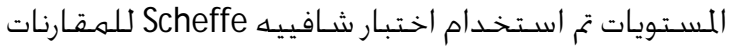

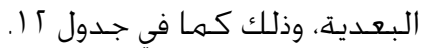

$$
\text { جدول } 11
$$

تحليل التباين الثثلاتي للاستجابات على مقياس الاتجاهات نحو البيئة وفقا

\begin{tabular}{|c|c|c|c|c|c|}
\hline الدلالة & قيمة & متوسط & درجة & مجموع & مصدر \\
\hline الإحصائية & ف & المربعات & الحرية & المربعات & التباين \\
\hline$\cdot, \wedge \Gamma \wedge$ & $\cdot, \cdot \leq Y$ & $\cdot, \cdots \leq$ & 1 & $\cdot, \cdots \leq$ & الجنس \\
\hline$\cdot, \cdot r t$ & $r, T \times 1$ & וTr, & r & אדוד, • & التخصص \\
\hline \multirow[t]{3}{*}{$\cdot, 00 \mathrm{~V}$} & ש97, & זדת , , & r & $\cdot, 1 \wedge \vee$ & المستوى \\
\hline & & $\cdot, .9$. & $\varepsilon r r$ & $r \wedge, 1 \leq \tau$ & الخطأ \\
\hline & & & $\varepsilon r q$ & $r q, \cdot r v$ & الكلي \\
\hline
\end{tabular}

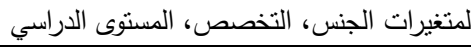

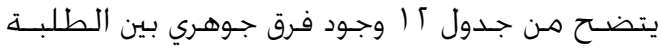

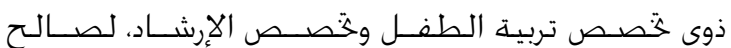

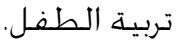


التباين الثلاثي عديم التفـاعل، على المتوسـطـات الحســابية

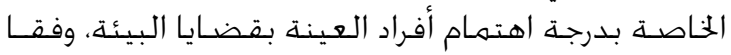

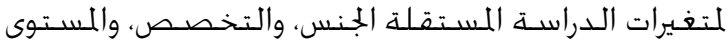

$$
\text { الـدراسـي كما في جدول } 1 \text { (. }
$$

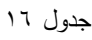

تحليل التباين الثلاثي لدتوسط الاستجابات على مقياس الاهتمام بقضايا البيئة

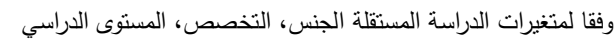

\begin{tabular}{|c|c|c|c|c|c|}
\hline الإحصائية & قيمة ف & المربعات & درجة & مجموع & التباين \\
\hline$\cdot, \cdots$ & $\left.r_{0, \varepsilon}\right)$. & $9,7 \wedge \varepsilon$ & 1 & $9,7 \wedge \varepsilon$ & الجنس \\
\hline$\cdot$, YA. & $1, r \vee Y$ & •, $\{\wedge \uparrow$ & r & $\cdot, 9 \vee \Gamma$ & التخصص \\
\hline \multirow[t]{3}{*}{.,. YY } & $r, r r$. & I,rTI & $r$ & r., & الدراستى \\
\hline & & • & ErT & $|7|, r \mid V$ & الخطأ \\
\hline & & & $\varepsilon r q$ & IVT,QIY & الكلي \\
\hline
\end{tabular}

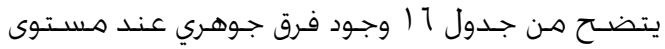

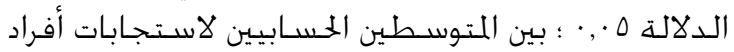

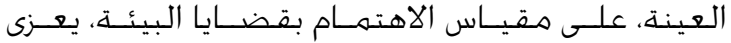

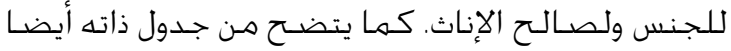

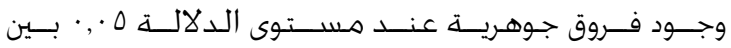
المتوسـطات الحسـابية للاسـتجابات على مقيـاس الاهتمام

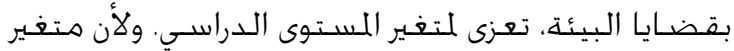

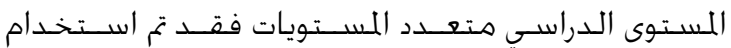

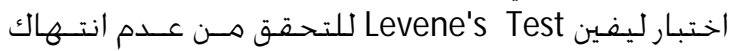

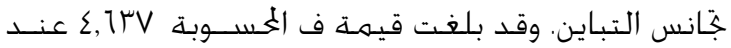

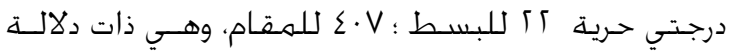

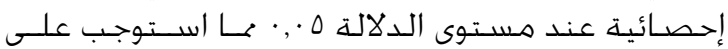
الباحثين استـخـدام اختبار جيهــز - هــاول Games-Howell

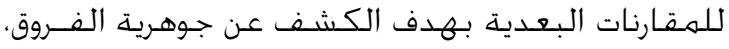

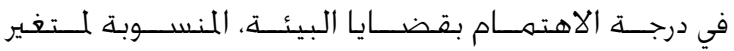

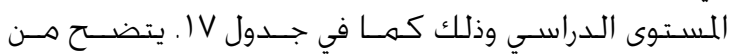

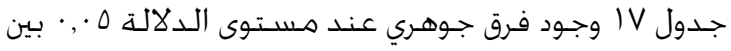

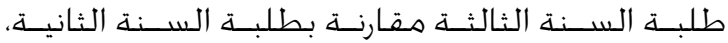
ولصـالح طلبة السـنة الثالثة.

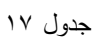

المقارنات البعدية بين متوسط الاستجابات على مقياس الاهتمام بقضايا البيئة وفقا

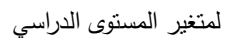

\begin{tabular}{|c|c|c|c|c|c|}
\hline ثالثة & رابعة & أولى & ثانية & & الدراسيتوى \\
\hline \multirow[t]{5}{*}{$r, \wedge 9 \varepsilon$} & r,Aro & r,AY & r,T V & الحسابي & جيمز - هاول \\
\hline & & & & r, זדV & ثانية \\
\hline & & &., $10 \mathrm{~V}$ & $r, \wedge r \varepsilon$ & أولى \\
\hline & & $\cdot, \cdots)$ &., 101 & r,Aro & رابعة \\
\hline & $\cdot, .79$ & $\cdot, \cdot V_{1}$ & •, YYA & $r, \wedge q \leq$ & ثالثة \\
\hline
\end{tabular}

جدول ؛ الإبن

تحليل التباين الثاثي لمتوسطات الاستجابات على مقياس الممارسات البيئية

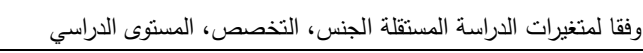

\begin{tabular}{|c|c|c|c|c|c|}
\hline الدلالة & قيمة & متوسط & درجة & مجموع & مصدر \\
\hline الإحصائية & ف & المربعات & الحرية & المربعات & التباين \\
\hline$\cdot, \cdot v \varepsilon$ & $r, r \cdot q$ & $1, \ldots \varepsilon$ & 1 & $1, \ldots \varepsilon$ & الجنس \\
\hline., 0.1 & $r, .1 \varepsilon$ & - & r & 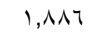 & التخصص \\
\hline \multirow[t]{3}{*}{$\cdot, \varepsilon Y \gamma$} & ., $9 Y V$ & ., rq. & $r$ & •,AVI & المستوى \\
\hline & & rוז, & \& & ITr,TOS & الخطأ \\
\hline & & & $\varepsilon r q$ & $\mid r v, r v$. & الكلي \\
\hline
\end{tabular}

يتضـح مـن جـدول ع ( عدم وجـود فـروق جوهـريــة ذات

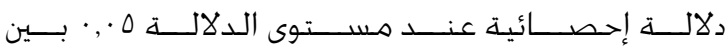

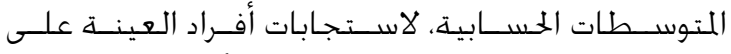

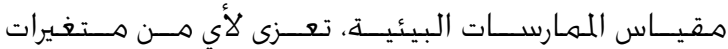
الـدراسـة المسـتقلة.

\section{رابعا: - فيما يتعلق بدرجة الاهتمام بقضـايا البيئة،}

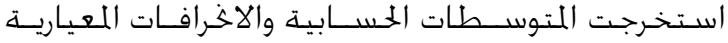

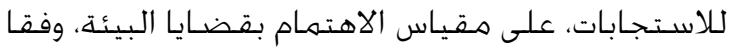

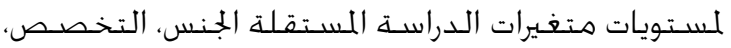

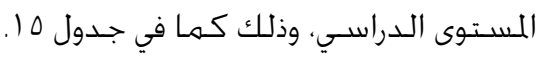

جدول 10

المتوسط الحسابي والانحراف المعياري للاستجابات على مقياس الاهتمام بقضايا البيئة وفقا لمستويات متغيرات الدراسة المستقلة

\begin{tabular}{|c|c|c|c|}
\hline الانحراف & الحسابي & المستويات & المتغيرات المستقلة \\
\hline$\cdot, 91$ & $r, r r)$ & ذكر & الجنس \\
\hline., $0 \mathrm{~V}$ & $\Gamma, \wedge \leq \uparrow$ & أنثى & \\
\hline$\cdot, 01$ & r,Aтo & معلم صف & التخصص \\
\hline זT, & r,vav & تربية طفل & \\
\hline$\cdot, \mathrm{\vee} \wedge$ & $r, 797$ & إرشاد & \\
\hline., 09 & r,ATS & أولى & المستوى الدراسي \\
\hline , VV & Vד, & ثانية & \\
\hline$\cdot, 00$ & 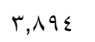 & ثالثة & \\
\hline$\cdot, 0 \leqslant$ & r,Aro & رابعة & \\
\hline
\end{tabular}

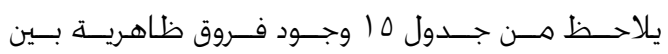

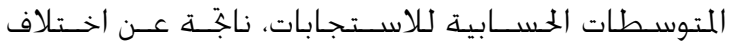

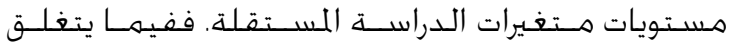

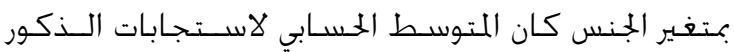

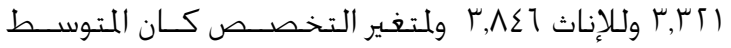

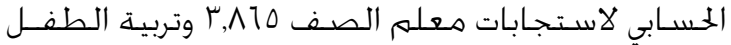
r, r,V9V

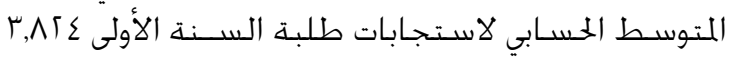

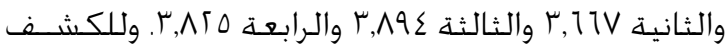

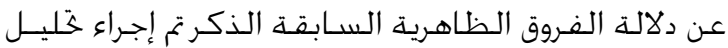


وتؤكـد اسـتجـابات الطلبة على الفـقرات السـطحـية

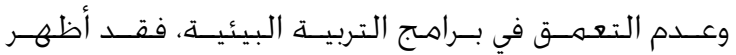

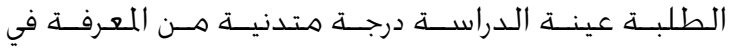
مفاهيم بيئية بسـيطة: كمفهوم النظام البيئي، والمـورد

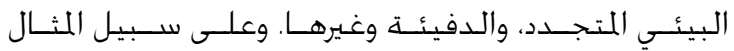

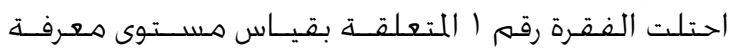

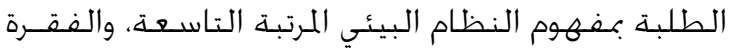

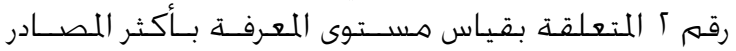
هسـاهــة في تلويث الهواء المرتبة العاشـرة.

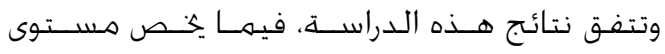

المعرفة البيئية، مع نتائج العديد مــن الـراســات ومهنـها:

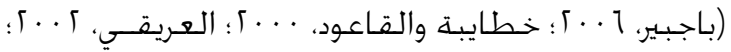

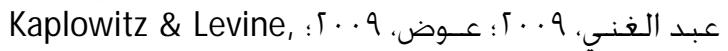
2005; M ichail, Stamou \& Stamou, 2007; Tuncer et (al., 2009; Amirshokoohi, 2010

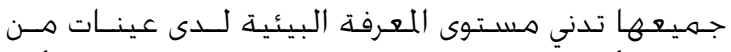

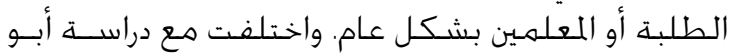

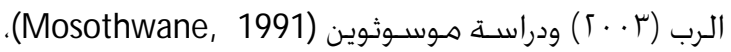

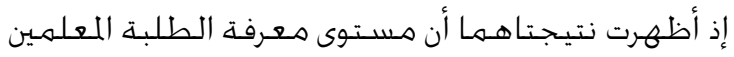

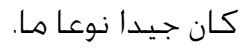

أهما ما يتعلق بمسـتوى الاجّاهـات البيئية، تتفقق نتائج

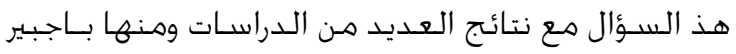

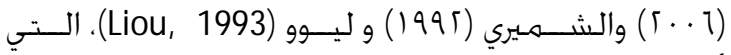

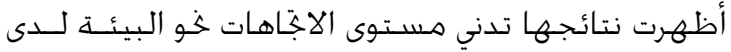

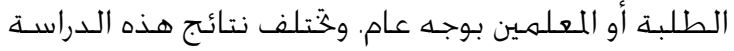

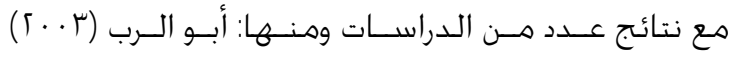
والنــاري (199V) وهسبـــو وروث (Hsu \& Roth, 1999)

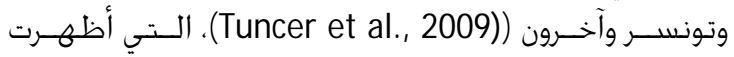

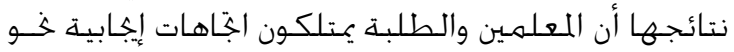
البيئة بصـورة مقبـولة.

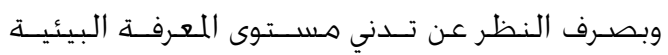

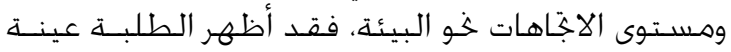

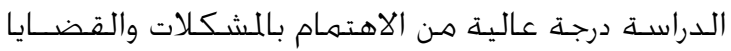

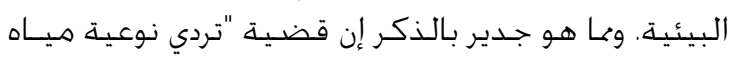

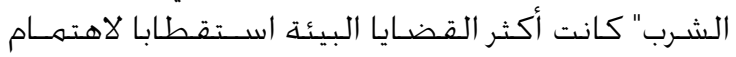

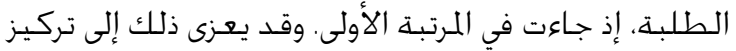

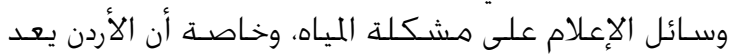

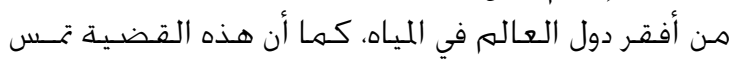

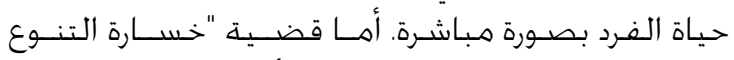

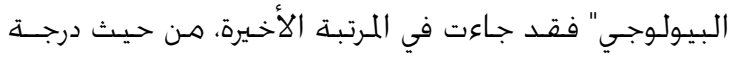

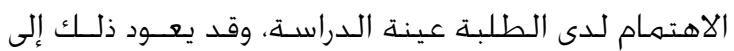

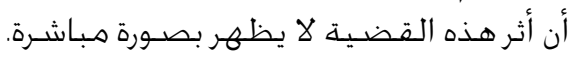

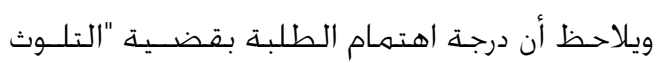

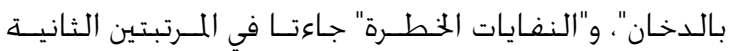

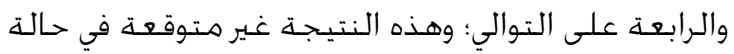

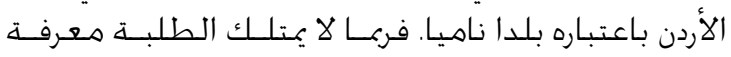

\section{مناقشة النتائج}

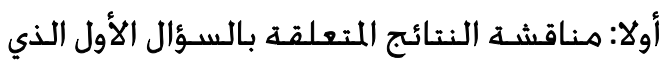

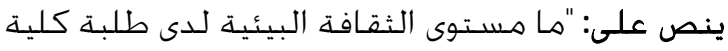

التربية في جامعـة اليرهوك؟

أظهرت النتـائج، المتعلقـــة بالإجابـة عـن هــذا

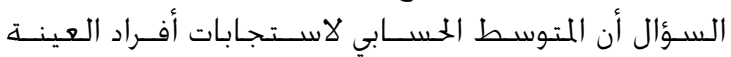

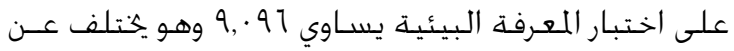

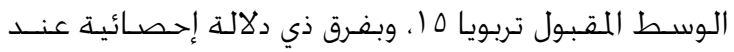

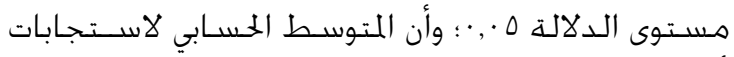

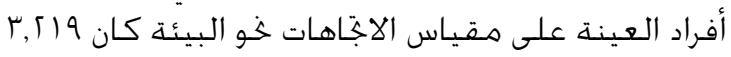

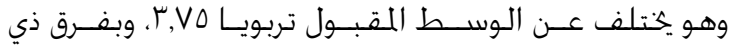

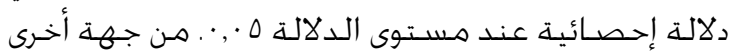

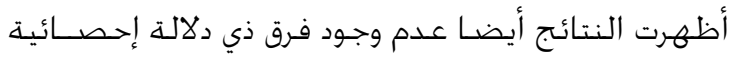

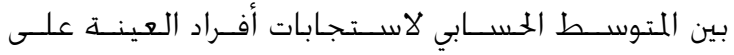

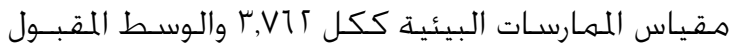

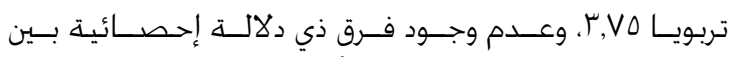

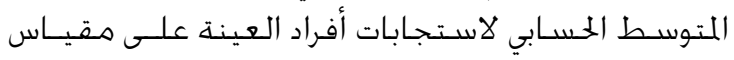

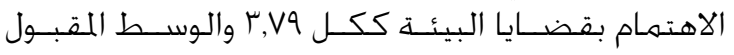

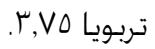

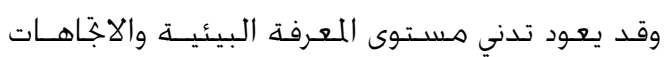

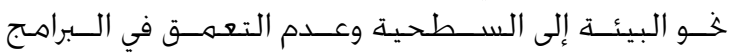

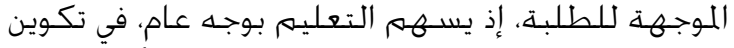

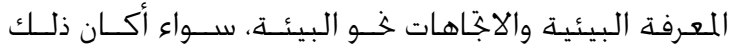

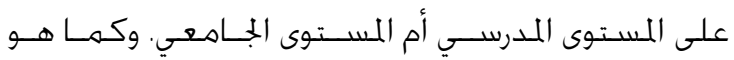

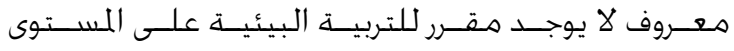

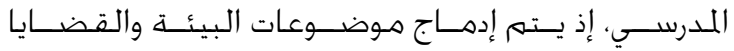

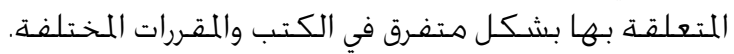

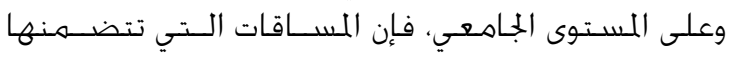

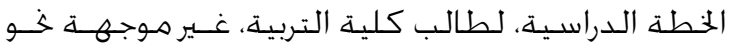

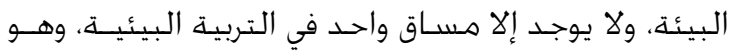

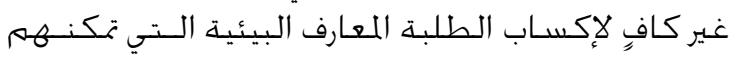

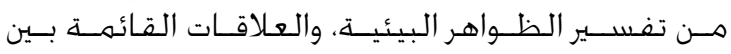

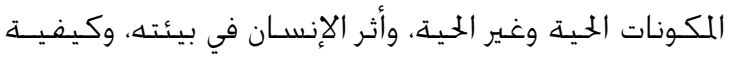

التعامل معها.

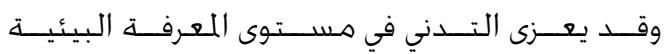

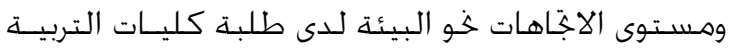

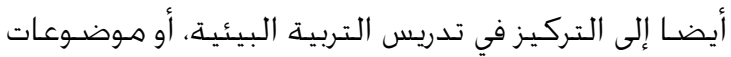

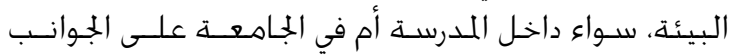

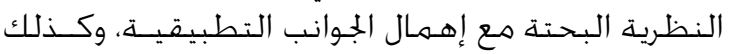

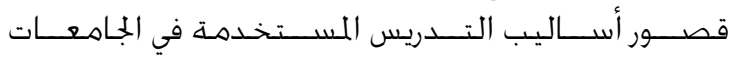

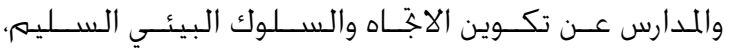

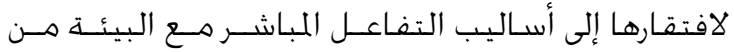

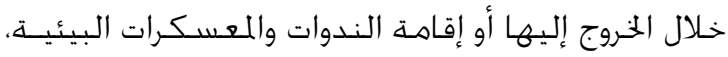

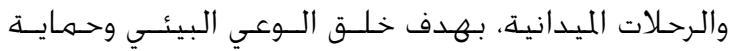
البيئة. 


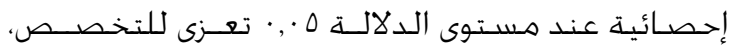

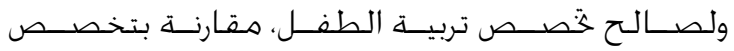

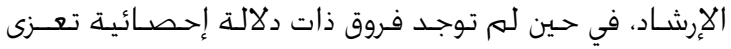

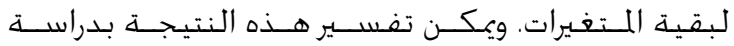

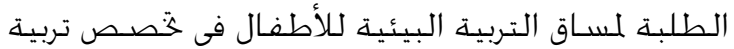

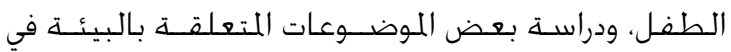

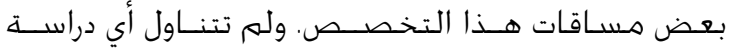

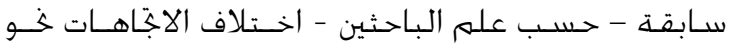

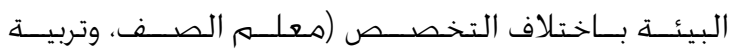

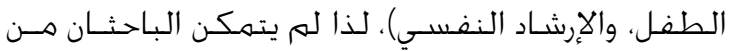

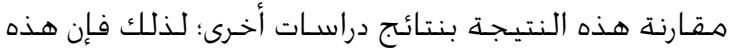

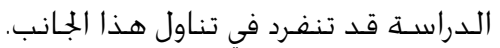

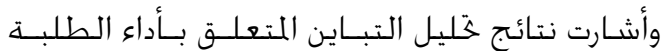

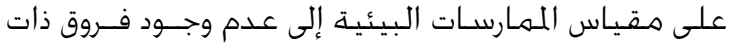

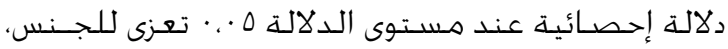

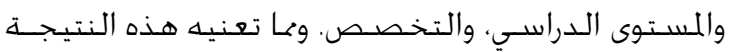

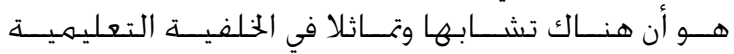

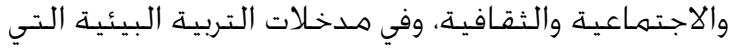

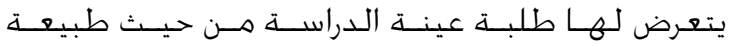

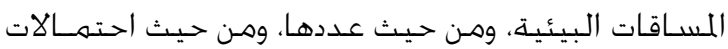

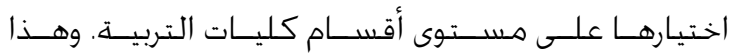

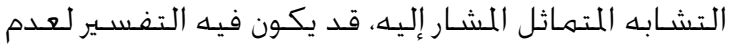

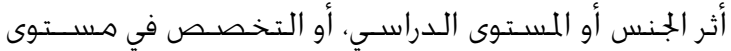

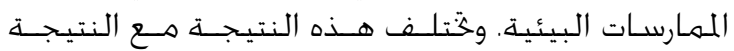

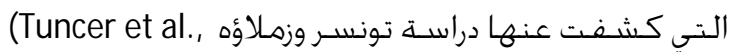

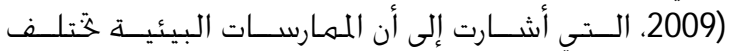
باختـلاف الجنسس، ولصـالح الإناث.

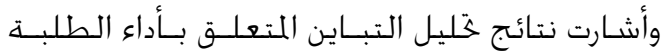

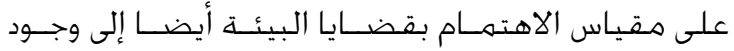

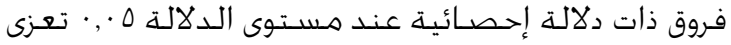

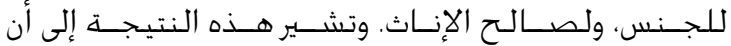

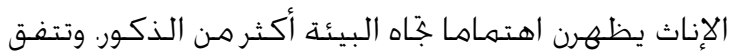

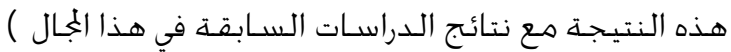
Tikka et al., 2000; Tuncer et al., 2009; Zelenzy,

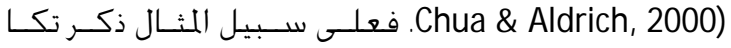

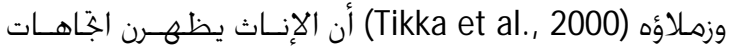

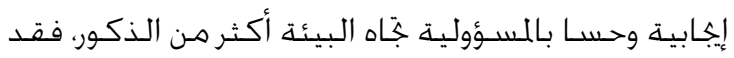

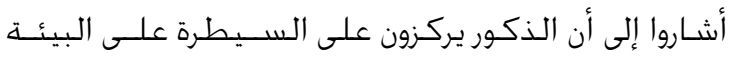

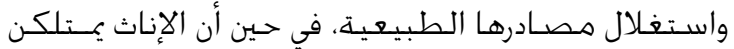

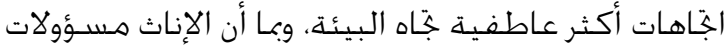

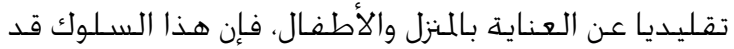
ينظر إليه كرعاية أبنائهن.

وبمهوازاة هذا التفسـير يشير الأدب التربوي إلى نظريتين

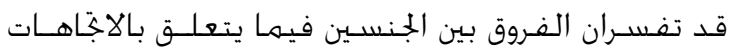

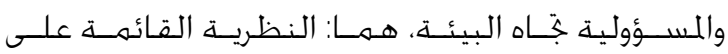

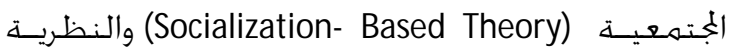

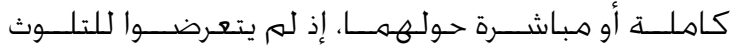

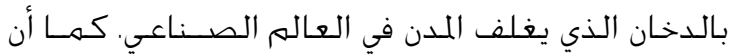

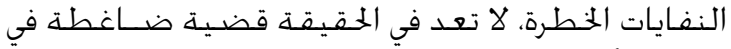

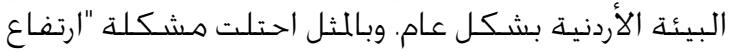

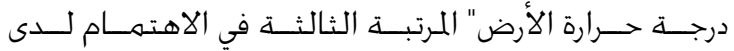

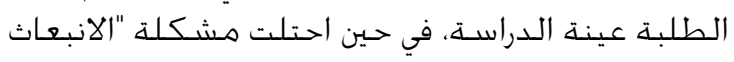

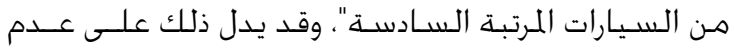

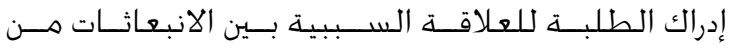

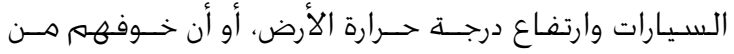

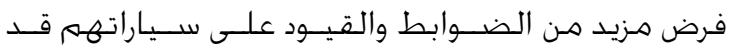

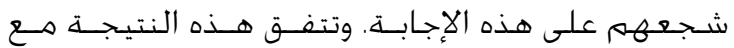

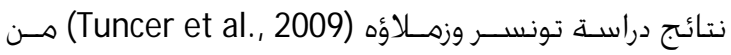

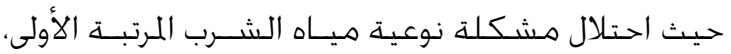

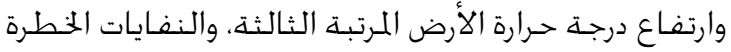
المرتبة الرابعة، في الاهتهمام لدى المعلمـين الطلبة.

ثانيا: مـناقشـــ النتائج المتعلقـة بالسؤال الثاني الذي

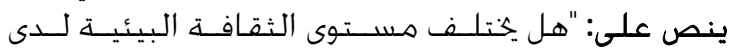

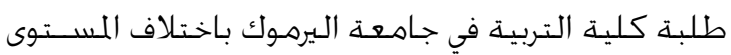

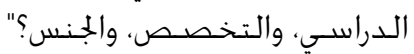

أشـارت نتائج خ خليـل التبـاين الثلاثـي المتعلـق بـأداء

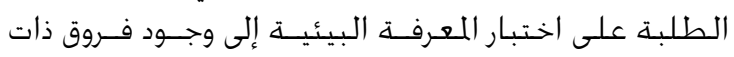

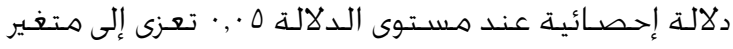

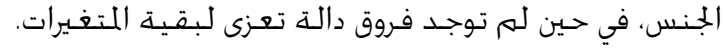
وقد يعزى تفـوق الإناث بـدلالة إحصـائية على الذكـور

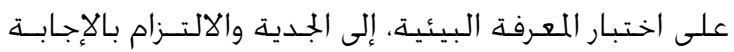

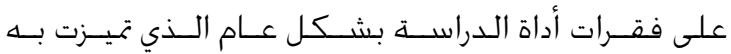

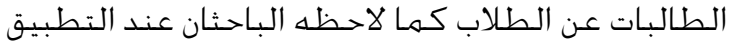

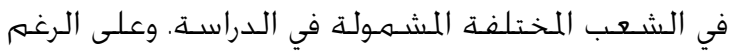

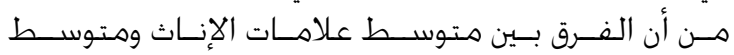

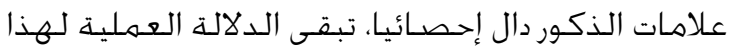

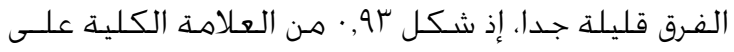

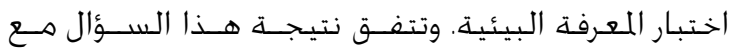

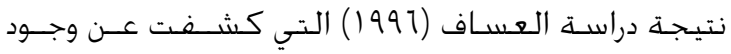

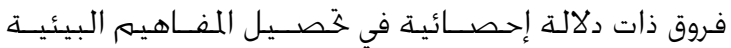

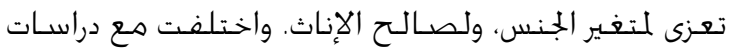

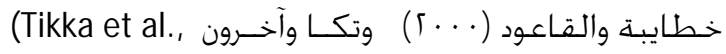

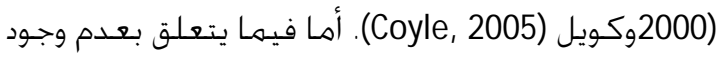

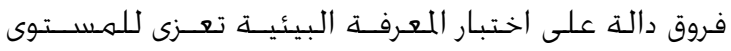

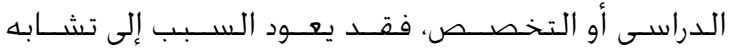

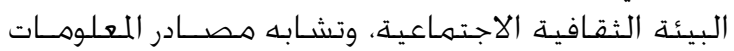

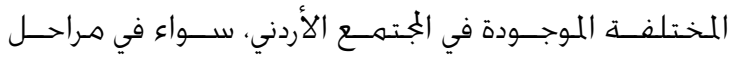

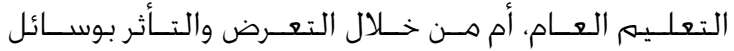

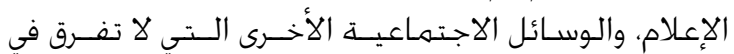
عملية التوعية بين الذكور والإناث.

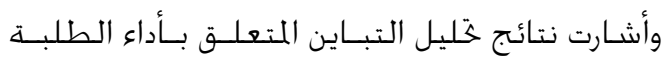

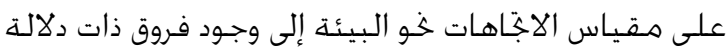




التوصيــات:

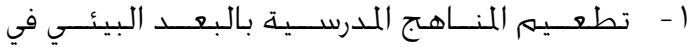

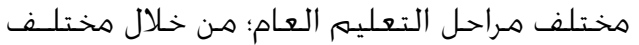

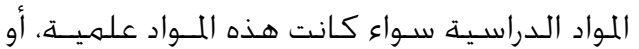

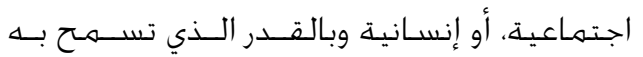

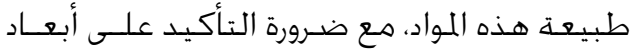
الثقافة البيئية المختلفة هذهة

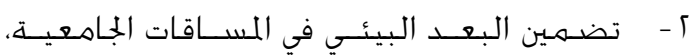

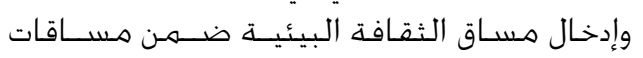

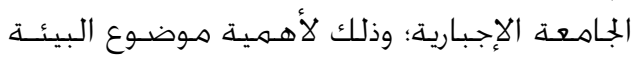

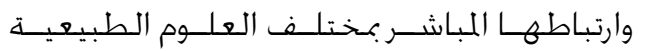
والإنسانية.

r - تكثيــف مشــاريع التخـــرج للطــلاب في كليـات

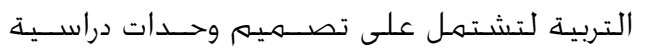

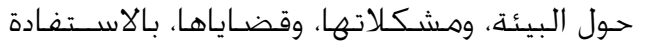
هـن تكنولوجيا التعليم المتطورة.

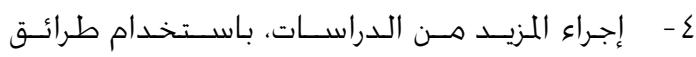

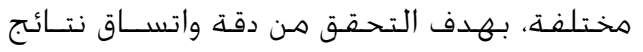

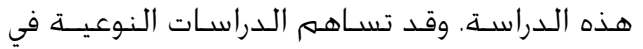

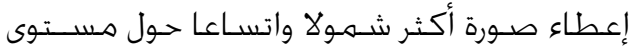
الثقافة البيئية لدى الطلبة في المرحلة الجامعية.

\section{المر اجع}

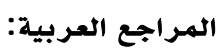

إبراهيم، مجدي (9 . ). معجـم مصـطلحات ومفــاهيم

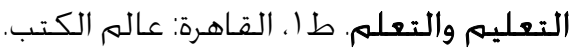

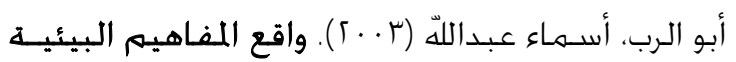
لدى طلبة الصف الثاني الثانوي في محافظة جنين.

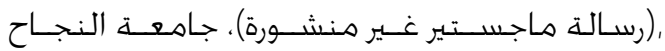
الوطنية، نابلس، فلســين.

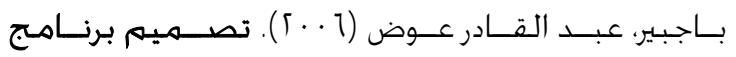

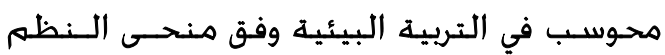

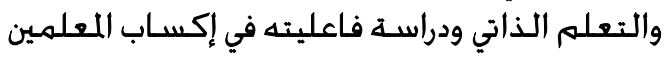

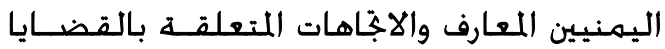
والمفاهيم والمشكـلات البئية (رسـالة دكتـوراه غـير الماهير منشـورة)، الجامعـة الأردنية، عـمان، الأردن.

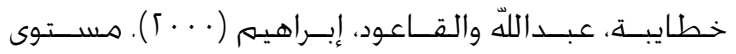

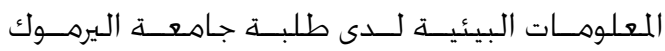

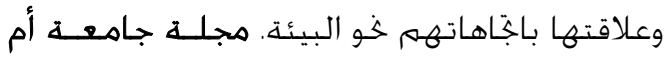

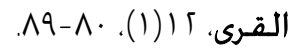

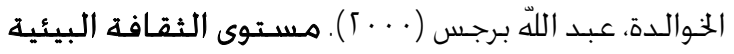

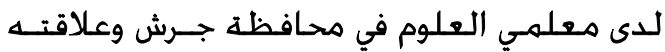

القـائمـــة علــى البنيويـــ (Structural Theory). فـوفقـــا

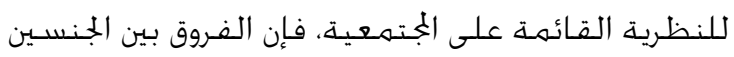

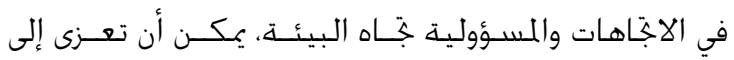

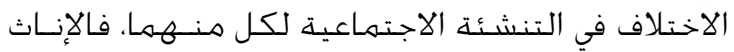

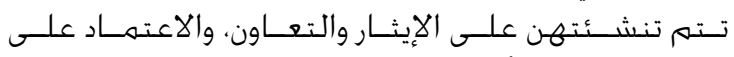

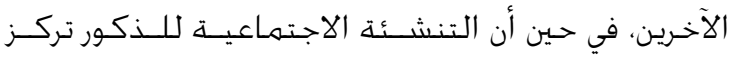

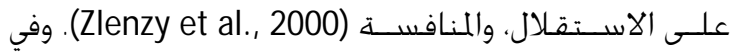

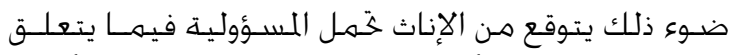

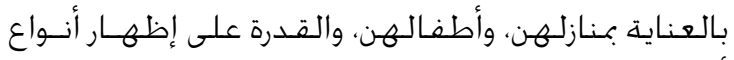

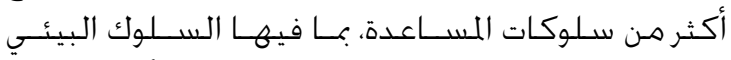

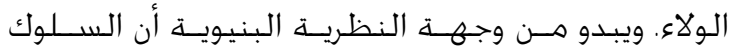

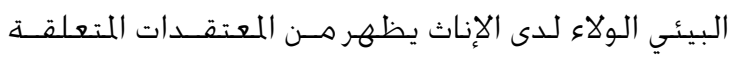

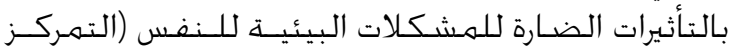

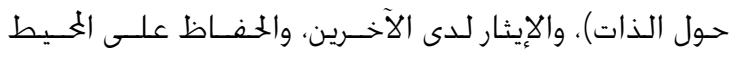

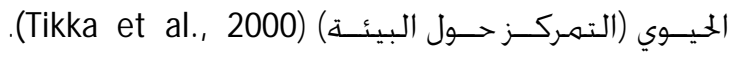

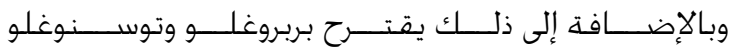
(Berberoglu \& Tosunoglu, 1995)

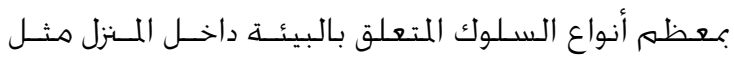

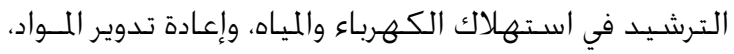

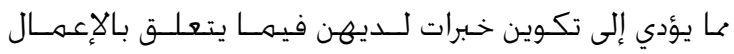

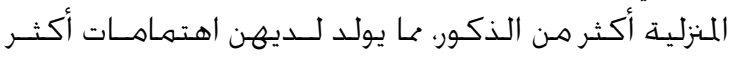
بالمشكلات والقضضـايا البيئية.

وتعـد موضـوعات البيئة ملائمـة لاهتمـامـات الإنـاث

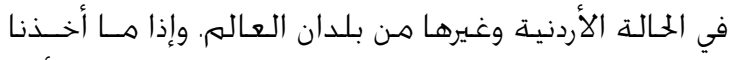

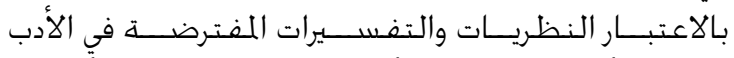

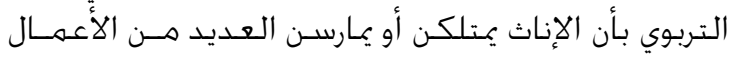

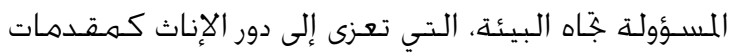

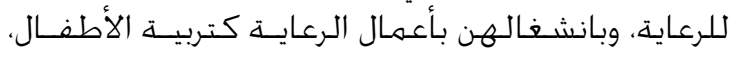

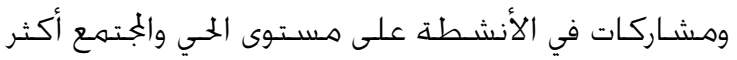

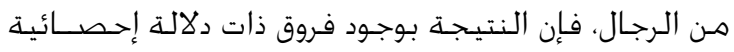

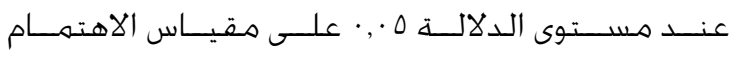

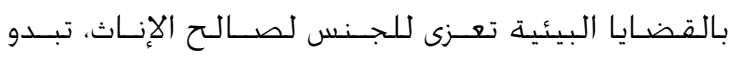

متوقعة.

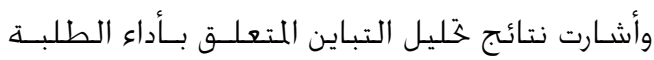

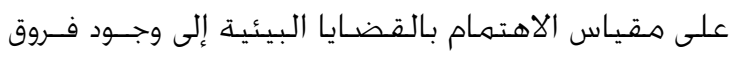

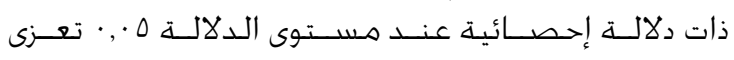

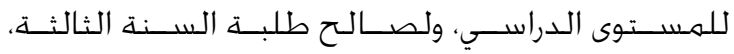

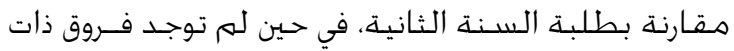

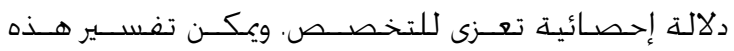

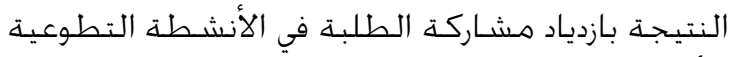

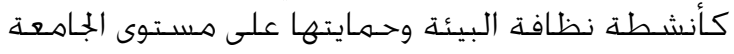

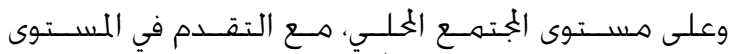

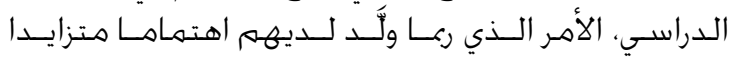

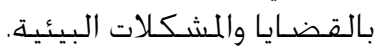


صـنعاء ومصـادر اكتسـابهم لها (رسـالة ماجسـتير غـير منشــورة)، جامعـة اليرموك، اربـد، الأردن.

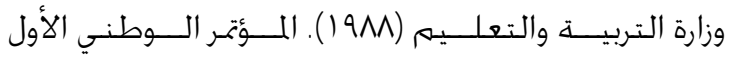

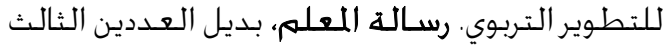

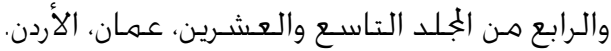

وزارة التربية والتعليم (ه . . ؟). الإطار العـام والنتاجـات

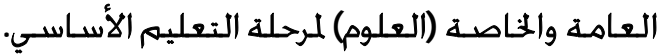

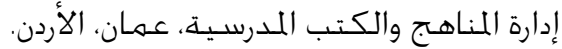

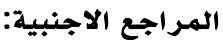

Alp, E., Ertepinar, H., Tekkaya, C., \& Yilmaz, A. (2006). A statistical analysis of children's environmental knowledge and attitudes in Turkey. International Research in Geographical and Environmental Education, 15(3), 210-223.

Amirshokoohi, A. (2010). Elementary preservice teachers environmental literacy and view toward science, technology and society (STS) issues. Science Educator, 19, 56-63.

Berberoglu, G. \& Tosunoglu, C., (1995). Exploratory and confirmatory factor analyses of an environmental attitude scale (EAS) for Turkish university students. The Journal of Environmental Education, 26, 40-44.

Bueth, C. \& Smallwood, J.(1987). Teachers' environmental literacy: Check and recheck, 1975 and 1985. The Journal of Environmental Education, 18(3), 39-42.

Cumming, Bob. (1994). Beyond Work For Literacy: The Hidden Opportunities of Environmental Literacy. New Directions for Community Colleges, n85, p61-76 Spr.

Coyle, K. (2005). Environmental Literacy in America. The National Environmental Education Training Foundation, Washington, DC.

Dietz, T., Fitzgerald, A. \& Shwom, R. (2005). Environmental values. Annual Review of Environment and Resources, 30, 335-372.

Disinger, J.F. \& Roth, C.E. (1992). Environmental literacy. ERIC/CSMEE Digest. Retrieved April 10, 2011 from http:/ / eric.ed.gov/ ERICDocs/ data/ ericd ocs2.

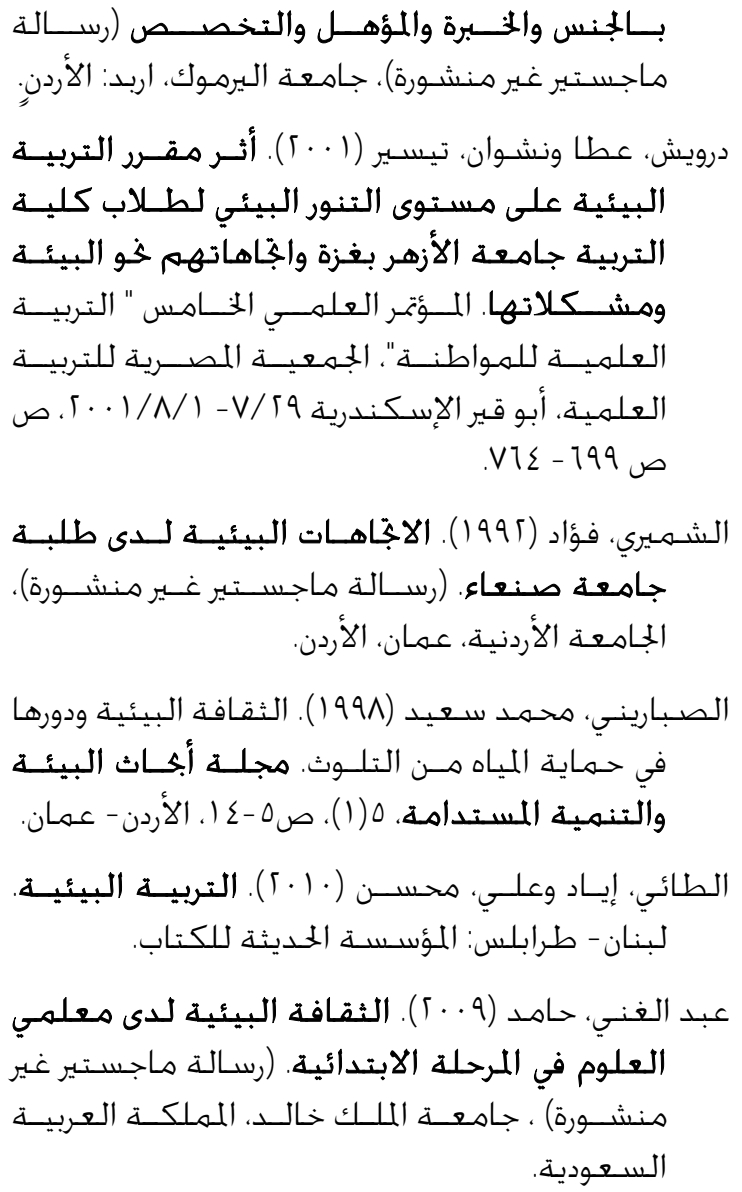


Erdogan, M.; Kostova, Z. \& Marcinkowski, T. (2009). Components of environmental literacy in elementary science education curriculum in Bulgaria and Turkey. Eurasia Journal of $M$ athematics, Science \& Technology Education. 5(1), 15-26.

Gilberston, K.L.(1990). Environmental literacy: outdoor education training and its effect on knowledge and attitudes toward environment. Dissertation A bstract International, 51(12): 4018A.

Goldman, D., Yavetz, B. \& pe'er, S. (2007). Environmental literacy in teacher training. attitudes, knowledge and environmental behavior of beginning students. Journal of Environmental Education, 39(1), 45-59.

Hsu, S.(2004). The effect of an environmental education program on responsible environmental behavior and associated environmental literacy variables in Taiwanese college students. Journal of Environmental Education, 34(2), 229-249.

Hsu, S. \& Roth, R.E., (1999). Predicting Taiwanese secondary teachers' responsible environmental behavior through environmental literacy variables. Journal of Environmental Education, 30, 11-19.

Harvery, G. D. (1976). A conceptualization of environmental education. In J, Aldrich, et al. (Ed.), A Report of the N orth America Regional Seminar on Environmental Education, ED 143505.

Hungerford, H. R. \& Peyton, R. B. (1976). Teaching Environmental Education. Weston Walch, Portland, ME.

Hungerford, H.R.\& Tomera, A.(1985). Science methods for the elementary school. Eric D ocument: ED 260921.

Kaplowitz, M.D. \& Levine, R. (2005). How environmental knowledge measures up at a big ten university. Environmental Education Research 11, 143-160.

Liou, J. (1993). Environmental knowledge, attitudes, behavior, intention, and behavior of pre-service elementary teachers in Taiwan, the Republic of China (Doctoral Dissertation, University of Florida, 1992), Dissertation Abstracts, services N o: Aac9314264.

Michail, S., Stamou, A. \& Stamou, G. (2007). Greek primary school teachers' understanding of current environmental issues: an exploration of their environmental knowledge and images of nature. Science Education, 91, 244- 259.

Morrone, M., Mand, K. \& Carr, K. (2001). Development of a metric to test group differences in ecological knowledge as one component of environmental literacy. The Journal of Environmental Education, 32, 3342.

Mosothwane, Modedcse, ED. D. (1991). Assessment of Botswana pre-service teachers environmental education and concerns for environmental quality. Dissertation A bstract International, Vol. 52. No. 6.

NAAEE. (2004). The environmental education collection: A review of resources for educators. Vol.1. Retrieved Feb 24, 2011, from the World Wide Web: http:/ / naaee.org/ npee/ resourcecollection -intro.html \#whyee.

Ozden, M. (2008). Environmental awareness and attitudes of student teachers: An empirical research. International R esearch in Geographical and Environmental Education, 17(1), 40-55.

Robinson, M., Tibanyendera, B. \& SeltzerKelly, D. (2007). Knowledge and attitudes of Ugandan pre-service science and mathematics teachers toward global and Ugandan science- and technology-based problems and/ or threats. Bulletin of Science, Technology Society, 27, 142-153.

Roth, C.E. (1984). Elements of a workable strategy for developing and maintaining nationwide environmental literacy. $N$ ature Study, 37(3), 46-48.

Roth, C.E. (1992). Environmental Literacy: Its Roots, Evolution and Directions in the 1990s. ERIC/ CSMEE Publications.

Spork, H., (1992). Environmental education: a mismatch between theory and practice. Australian Journal of Environmental Education, 8, 147-166.

Tikka, P.M., Kuitunen, T.M. \& Tynys, M.S. (2000). Effects of educational background on students' attitudes, activity levels, and knowledge concerning environment. The Journal of Environmental Education, 31, 1219.

Tuncer, G., Tekkaya, C., Sunger, S., Cakiroglu, J., Ertepinar, H .\& Kaplowitz, M. (2009). 
Assessing pre-service teachers' environmental literacy in turkey as a mean to develop teacher education programs. International Journal of Educational D evel opment, 29, 426- 436.

UNESCO. (1980). Environmental education in the light of Tbilisi conference. Paris, France.

Wilke, R. (1995). Environmental literacy and the college curriculum. EPA Journal, 21, 28-30.

Wright, J. M. (2008). The comparative effects of constructivist versus traditional teaching methods on environmental literacy of postsecondary non science majors. Bulletin of Science Technology Society, 28, 324 337. 